\title{
Cardinal Orientation Selectivity Is Represented by Two Distinct Ganglion Cell Types in Mouse Retina
}

\author{
Amurta Nath ${ }^{1}$ and Gregory W. Schwartz ${ }^{1,2,3}$ \\ ${ }^{1}$ Interdepartmental Neuroscience Program, ${ }^{2}$ Department of Ophthalmology, and ${ }^{3}$ Department of Physiology, Feinberg School of Medicine, Northwestern \\ University, Chicago, Illinois 60611
}

Orientation selectivity (OS) is a prominent and well studied feature of early visual processing in mammals, but recent work has highlighted the possibility that parallel OS circuits might exist in multiple brain locations. Although both classic and modern work has identified an OS mechanism in selective wiring from lateral geniculate nucleus (LGN) to primary visual cortex, OS responses have now been found upstream of cortex in mouse LGN and superior colliculus, suggesting a possible origin in the retina. Indeed, retinal OS responses have been reported for decades in rabbit and more recently in mouse. However, we still know very little about the properties and mechanisms of retinal OS in the mouse, including whether there is a distinct OS ganglion cell type, which orientations are represented, and what are the synaptic mechanisms of retinal OS. We have identified two novel types of OS ganglion cells in the mouse retina that are highly selective for horizontal and vertical cardinal orientations. Reconstructions of the dendritic trees of these OS ganglion cells and measurements of their synaptic conductances offer insights into the mechanism of the OS computation at the earliest stage of the visual system.

Key words: ganglion cells; orientation selectivity; retina; retinal circuits

\section{Significance Statement}

Orientation selectivity (OS) is one of the most well studied computations in the brain and has become a prominent model system in various areas of sensory neuroscience. Although the cortical mechanism of OS suggested by Hubel and Wiesel (1962) has been investigated intensely, other OS cells exist upstream of cortex as early as the retina and the mechanisms of OS in subcortical regions are much less well understood. We identified two $\mathrm{ON}$ retinal ganglion cells (RGCs) in mouse that compute OS along the horizontal (nasal-temporal) and vertical (dorsoventral) axes of visual space. We show the relationship between dendritic morphology and OS for each RGC type and reveal new synaptic mechanisms of OS computation in the retina.

\section{Introduction}

Orientation selectivity (OS) is one of the fundamental computations of the mammalian visual system. In 1962, Hubel and Wiesel discovered neurons in primary visual cortex (V1) of the cat that respond selectively to bars of light in a particular orientation. They proposed a mechanism in which several concentric recep-

\footnotetext{
Received Dec. 21, 2015; revised Jan. 28, 2016; accepted Feb. 3, 2016.

Author contributions: A.N. and G.W.S. designed research; A.N. and G.W.S. performed research; A.N. and G.W.S. analyzed data; A.N. and G.W.S. wrote the paper.

This work was supported by a Research to Prevent Blindness Career Development Award, by the National Institutes of Health-National Eye Institute, and by a Karl Kirchgessner Foundation Vision Research Award. We thank Schwartz laboratory members for helpful discussions; Susan Lynn Wohlgenant for technical support and Micheal B. Manookin, William N. Grimes, Felice A. Dunn, and Jianhua Cang for reviewing this manuscript and providing important feedback.

The authors declare no competing financial interests.

Correspondence should be addressed to Gregory W. Schwartz, Departments of Ophthalmology and Physiology, Feinberg School of Medicine, Northwestern University, 300 E. Superior St, Tarry Building, Chicago, IL 60611. E-mail: greg.schwartz@northwestern.edu.

DOI:10.1523/JNEUROSCI.4554-15.2016

Copyright $\odot 2016$ the authors $\quad 0270-6474 / 16 / 363208-14 \$ 15.00 / 0$
}

tive fields in lateral geniculate nucleus (LGN) converge onto a single neuron in $\mathrm{V} 1$ and the specific wiring patterns of these feedforward connections endows the V1 neuron with OS. Substantial evidence has supported this model, including studies in mice (Lien and Scanziani, 2013). Other studies have shown, however, that there is another orientation-selective selective pathway in rodents and rabbits that begins upstream of V1. Three separate studies recently reported orientation-selective cells in mouse LGN and all argued against cortical feedback as the source of this phenomenon (Marshel et al., 2012; Piscopo et al., 2013; Zhao et al., 2013). Orientation selectivity has also been reported in the superficial layers of mouse superior colliculus (SC), another brain region that receives direct input from the retina (Wang et al., 2010; Ahmadlou and Heimel, 2015; Feinberg and Meister, 2015).

Does orientation selectivity begin in the retina or does it result from the convergence of non-OS retinal ganglion cells (RGCs) onto their postsynaptic targets? Marshel et al. (2012) proposed a model in which direction-selective (DS) RGCs, long known to 
exist in mouse retina, converge to form orientation-selective LGN cells. Cruz-Martín et al. (2014) used circuit tracing to demonstrate that DS RGCs contribute, through the LGN, to OS in V1. Zhao et al. (2013) instead suggested that OS might originate in the retina and identified putative OS RGCs in multielectrode array recordings, as did two other groups (Chen et al., 2014; Pearson and Kerschensteiner, 2015). A recent calcium-imaging study also identified several clusters of OS RGCs in the mouse, including both ON and OFF types (Baden et al., 2016). OS RGCs have been found in rabbit (Levick, 1967; Caldwell and Daw, 1978; Amthor et al., 1989; Bloomfield, 1994; He et al., 1998; Venkataramani and Taylor, 2010) and some degree of OS has been reported in macaque midget and parasol RGCs (Passaglia et al., 2002), but no specific OS RGC type has been reported in mouse and the multielectrode array studies have not reported the distribution of orientation preference or the contributions of different circuit elements (e.g., excitation, presynaptic vs postsynaptic inhibition, GABA vs glycine receptors).

We have discovered two OS RGC types in the mouse retina that represent the horizontal (nasal-temporal) and vertical (dorsoventral) axes of the visual field. We have characterized the response properties and morphology of these RGC types and explored the synaptic mechanisms giving rise to the OS computation in the retina. Our studies thus prove the existence of a dedicated OS circuit in the mouse retina and form the basis for future investigations of how retinal OS signals influence downstream brain areas and behavior.

\section{Materials and Methods}

Electrophysiology. Wild-type mice (C57BL/6) of either sex (37 male and 4 female) were dark adapted overnight. Animals were killed following animal protocols approved by the Center for Comparative Medicine at Northwestern University. Retina dissections were conducted under IR light $(940 \mathrm{~nm})$ with assistance from IR visible light converter (night vision) goggles and separate IR dissection scope attachments (BE Meyers). Cardinal directions were identified using scleral landmarks (Wei et al., 2010). Relieving cuts were made along cardinal directions and the whole retina was mounted ganglion cell side up on a $12 \mathrm{~mm}$ poly-Dlysine-coated glass coverslip (BioCoat Cellware; Corning) that was secured to a recording dish via grease. The dish was placed on the electrophysiology rig (SliceScope Pro 6000; Scientifica) and superfused with carbogenated Ames medium (Sigma-Aldrich, A-1420; $9 \mathrm{ml} / \mathrm{min}$ ) warmed to $32^{\circ} \mathrm{C}$. Tissue was illuminated at $950 \mathrm{~nm}$ for visualization. Cell-attached recordings were obtained with a 2-channel patch-clamp amplifier (MultiClamp 700B; Molecular Devices) using pipettes (2-3 $\mathrm{M} \Omega$ ) filled with Ames solution. For voltage-clamp experiments, pipettes (4-6 M $\Omega$ ) were filled with an intracellular solution composed of the following (in mM): 105 Cs methanesulfonate, 10 TEA-Cl, 20 HEPES, 10 EGTA, 2 QX-314, 5 Mg-ATP, and 0.5 Tris-GTP at $\sim 270 \mathrm{mOsm}, \mathrm{pH}$ $\sim 7.3$ with $\mathrm{CsOH}$. To isolate excitatory and inhibitory synaptic inputs, each ganglion cell was held at the reversal potential for inhibition $(\sim-60$ $\mathrm{mV}$ ) and excitation $(\sim 20 \mathrm{mV})$, respectively. Absolute voltage values were not corrected for a liquid junction potential of $-8.58 \mathrm{mV}$ in the Cs-based intracellular solution. Pharmacological reagents were purchased from Sigma-Aldrich (gabazine, strychnine, TPMPA, saclofen) and Tocris Bioscience (TTX). Drug concentrations were as follows: strychnine, $1 \mu \mathrm{M}$; gabazine, $10 \mu \mathrm{M}$; TPMPA, $50 \mu \mathrm{M}$; saclofen, $100 \mu \mathrm{M}$; TTX, $500 \mathrm{~nm}$. Other recording details are as in Jacoby et al. (2015).

Visual stimuli. A custom-designed light projection device (DLP LightCrafter; Texas Instruments) capable of controlling patterned visual stimulation at frame rates up to $1.4 \mathrm{kHz}$ was used to display visual stimuli. All spatial stimuli patterns were displayed on a $1280 \times 800$ pixel array with pixel size of $2-3 \mu \mathrm{m}$ and were focused onto the photoreceptor layer through the microscope condenser. The device used blue LED illumination with a peak spectral output at $450 \mathrm{~nm}$. Photon flux was attenuated to suitable levels using neutral density filters (Thorlabs) and light intensity values were measured in rhodopsin isomerizations per rod per second $\left(\mathrm{R}^{\star} / \mathrm{rod} / \mathrm{s}\right)$. During cell-attached recording, the RGCs' responses to horizontal and vertical bars $(200 \times 40 \mu \mathrm{m})$ across 11 locations along each axis spaced by $40 \mu \mathrm{m}$ were measured to obtain the spatial position of receptive field (RF) center. Subsequent stimuli were delivered at the RF center. Circular spots of $200 \mu \mathrm{m}$ diameter on a dark background were used to identify light-step profiles of RGCs. Spots of diameters ranging from 10 to $1200 \mu \mathrm{m}$ were used to characterize the temporal dynamics of RGC responses (see Fig. $2 E)$. Bars $(800 \times 50 \mu \mathrm{m})$ were flashed for $1 \mathrm{~s}$ at 12 different angles to characterize ON OS RGCs. Moving bar stimuli consisted of rectangular bars $(600 \times 50 \mu \mathrm{m})$ moving at $1000 \mu \mathrm{m} / \mathrm{s}$ for $3 \mathrm{~s}$ across the RF of RGCs. All such stimuli were presented at $200 \mathrm{R} * / \mathrm{rod} / \mathrm{s}$. Full-field sine wave drifting gratings were presented from a background intensity of $500 \mathrm{R}^{\star} / \mathrm{rod} / \mathrm{s}$ at a Weber contrast of $100 \%$. All stimuli with varying parameters were presented in pseudorandom order.

Immunohistochemistry. Tissues were fixed overnight in $4 \%$ paraformaldehyde (Electron Microscopy Sciences). Fixed retinas were incubated in PBS containing 3\% normal donkey serum (blocking agent), $0.05 \%$ sodium azide, $0.5 \%$ Triton $\mathrm{X}-100$, and primary antisera against ChAT (Millipore, AB144P, goat anti-ChAT, 1:500) for 5 nights at $4^{\circ} \mathrm{C}$. Afterward, tissues were rinsed in PBS and incubated overnight at $4^{\circ} \mathrm{C}$ with secondary antibody against goat IgG (Jackson ImmunoResearch, 705-475-147, donkey anti-goat DyLight 405, 1:500) and streptavidin (Pierce Biotechnology, 21832, DyLight 488, 1:500). After immunostaining, retinas were mounted on slides with p-phenylenediamine medium.

Imaging. Before whole-cell recordings, patch pipettes were filed with Alexa Fluor 488. After recording, RGC morphology was imaged using two-photon microscopy (920 nm, MaiTai HP; SpectraPhysics) under a $60 \times$ water-immersion objective [Olympus LUMPLan FLN 60×/1.00 numerical aperture (NA)]. Emission was collected by a $520-540 \mathrm{~nm}$ band-pass filter.

For dendritic stratification, target RGCs were injected via patch pipettes containing Neurobiotin tracer (Vector Laboratories, SP-1150, $\sim 3 \% \mathrm{w} / \mathrm{v}$ and $\sim 280 \mathrm{mOsm}$ in potassium aspartate internal solution).

Fixed tissues were imaged on a Nikon A1R laser scanning confocal microscope mounted on a Nikon Ti ZDrive PerfectFocus microscope stand equipped with an inverted $60 \times$ oil-immersion objective (Nikon Plan Apo VC $60 \times / 1.4$ NA). RGC dendrites and ChAT labeling were imaged at 488 and 405 or $647 \mathrm{~nm}$ excitation, respectively. All confocal images were collected with spacing of $0.2 \mu \mathrm{M}$ in the $z$-axis. Confocal imaging was performed at the Nikon Imaging Center at Northwestern University's Feinberg School of Medicine using Nikon Elements software. Dendritic arbors were traced using the Fiji software Simple Neurite Tracer plugin and subsequent Sholl analysis was performed. For dendritic stratification profiles, similar program and methods were used as described in (Sümbül et al., 2014).

Data analysis. The light-step response profiles of ON OS and other ON and ON-OFF RGCs were subdivided into transient $(0-200 \mathrm{~ms})$ and sustained (200-1000 ms) temporal time windows. Peak firing rates in these time windows were calculated from peristimulus time histograms of light-step responses. Peak interspike interval (ISI) was calculated in a $100-500 \mathrm{~ms}$ time window and was averaged across all light-step trials for a single cell. Orientation selective index (OSI) and preferred orientation angle were calculated based on a standard metric of the circular variance. Vector sum of the responses across orientations is given by the following:

$$
\frac{\sum R(\theta) e^{2 i \theta}}{\sum R(\theta)}
$$

where $R(\theta)$ is the response for $\theta$ orientation across the entire stimulus time window for both flashed bars and moving bars. Absolute value and half the phase of the resultant complex number give the values of the OSI and OS angle, respectively.

For population average tuning curves (see Fig. $1 E, F$ ), each flashed bar or moving bar response was normalized to maximum, the maximum responses were circularly shifted to the same preferred angle across cells, and the response was averaged across every bar angle. In Figure $1,0^{\circ}$ was chosen as the common preferred angle. For subsequent figures, no circular shift was performed and angles are reported in visual space. 
A

ON OS

ON alpha

ON DS
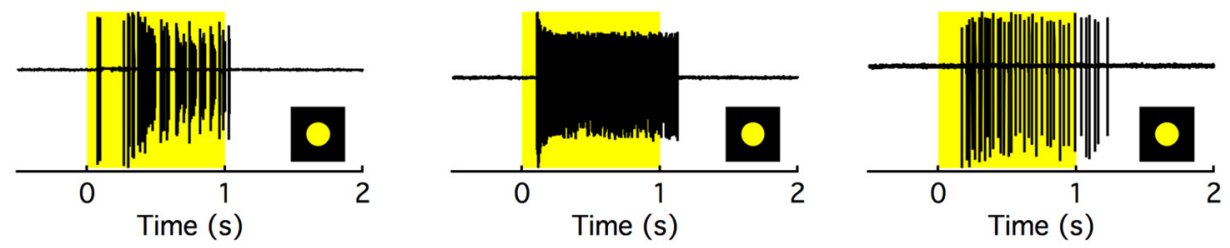

B

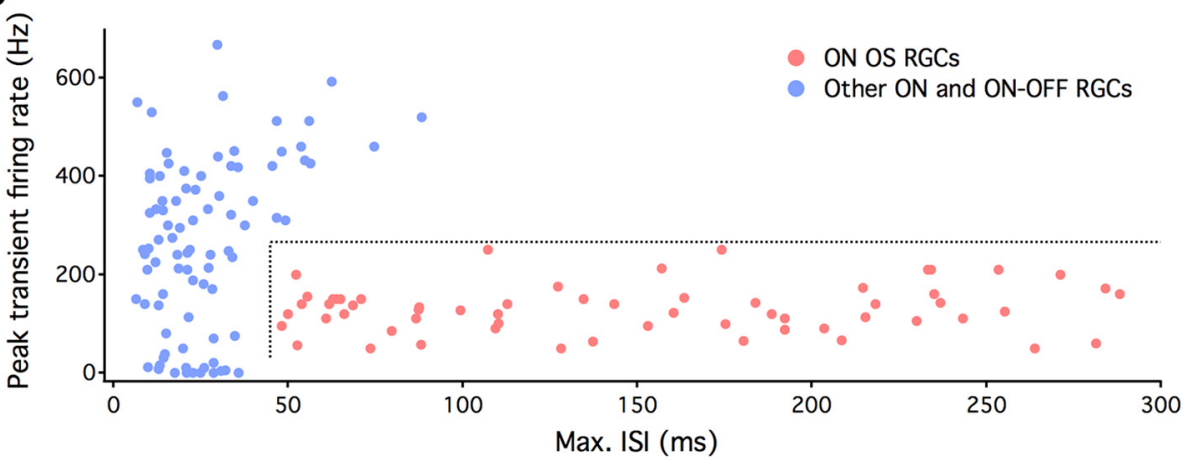

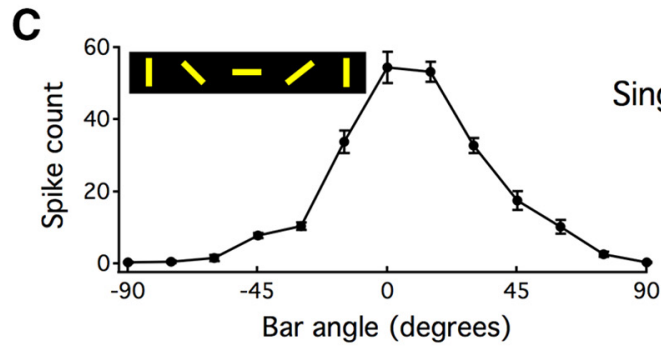

Preferred

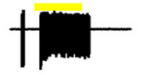

E

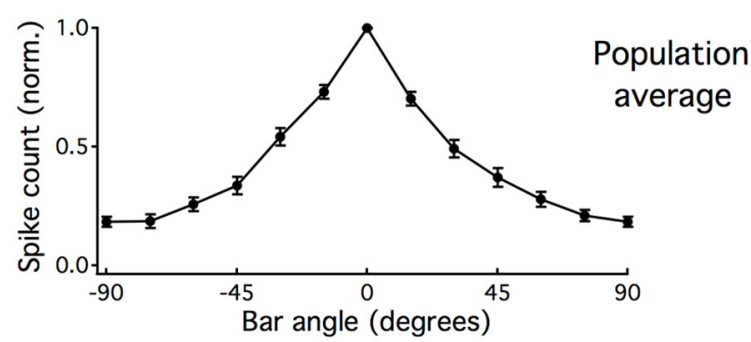

G

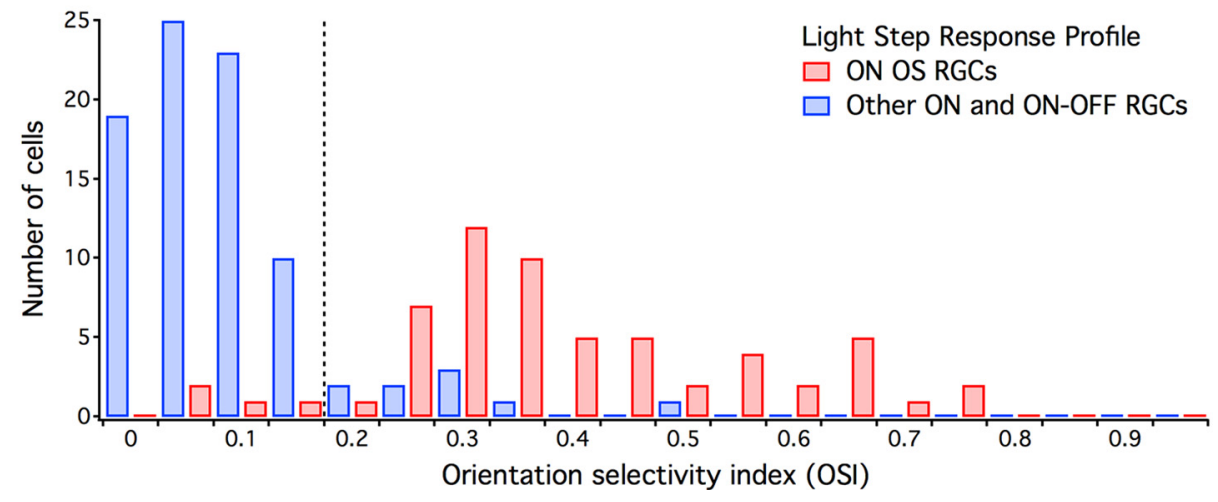

D

Single cell

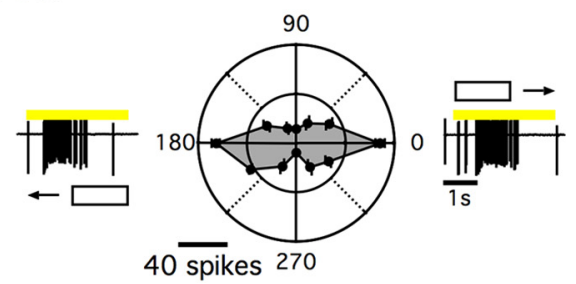

\#†\#口!

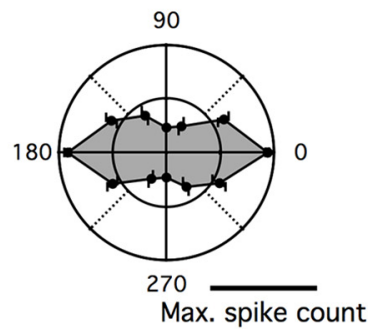

Max. spike count

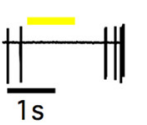

F 
For computing the axis ratio, the RGC dendritic field was fitted with a polygon using a custom-written MATLAB package (github.com/ SchwartzNU/SymphonyAnalysis). The maximum distance of two points lying on the polygon perimeter was used as the major axis length. Minor axis length was calculated as the longest line segment perpendicular to the major axis with ends lying on the polygon perimeter. Axis ratio was the fraction of these two lengths. Axis ratio was calculated separately for $\mathrm{ON}$ and OFF dendrites. The polygon perimeter was resampled into 1000 points and the centroid was computed. Vectors were constructed from the centroid to the perimeter points and the vector sum calculated similarly using the above equation. Half of the complex phase of the sum gives the preferred orientation of the dendrites.

All electrophysiological data were analyzed with a custom open-source MATLAB analysis package described above and figures were constructed in Igor version 6.36 (Wavemetrics).

\section{Results}

We identified two subtypes of ON orientation-selective retinal ganglion cells (ON OS RGCs) in a dark-adapted, ex vivo preparation of mouse retina (Murphy and Rieke, 2006; Schwartz et al., 2012). The following sections described the characteristics of the light responses of ON OS RGCs, dendritic morphology and its relationship to orientation preference, the presence of OS in both excitatory and inhibitory synaptic conductances of ON OS RGCs, and the pharmacological profiles of these newly discovered OS conductances.

\section{Functional characterization of ON OS RGCs}

We performed a large-scale screen of the light response properties of mouse RGCs recorded individually in cell-attached configuration. In total, we report recordings from 146 RGCs from 67 retinas (41 mice). As part of our functional screen, we encountered a set of RGCs with a distinct spiking pattern to a $1 \mathrm{~s}$ step of light from darkness confined to the RF center (see Materials and Methods). These newly identified RGCs responded with a sustained volley of spikes at light onset, but details of the spike pattern were distinct from two other known sustained ON RGCs (Fig. 1A). These cells responded with a brief burst of spikes followed by a pause and then a sustained discharge throughout the step. The details of this light response, most notably the pause between transient and sustained spike responses, were unique to these RGCs. For all ON and ON-OFF RGCs recorded, we measured the peak transient firing rate (within the first $200 \mathrm{~ms}$ ) and the maximum interspike interval (ISI) (averaged over trials, see Materials and Methods) during the $1 \mathrm{~s}$ light step. These RGCs formed a distinct cluster in this 2D space and were formally classified by a peak transient firing rate $<260 \mathrm{~Hz}$ and a maximum ISI $>45$ ms (Fig. 1B).

Figure 1. ON OS RGC is a distinct functional cell type. $A$, Responses of ON OS (left) ON alpha (middle) and ON direction selective (right) RGCs to a 1 s flash of $200 \mu \mathrm{m}$ diameter circular light spot. Yellow rectangle indicates period of light stimulus. $\boldsymbol{B}$, Peak transient firing rate plotted against peak ISI for ON OS $(n=60)$ and non-OS $(n=86)$ RGCs. Dotted lines indicate peak transient firing rate $=260 \mathrm{~Hz}$ and peak $\mathrm{ISI}=45 \mathrm{~ms}$. C, Spike responses of an example ON OS RGC to oriented light bar stimuli ( $800 \mu \mathrm{m} \times 50 \mu \mathrm{m}, 12$ angles). Preferred and null orientation responses are shown below. Error bars indicate SEM across five trials at each orientation. $\boldsymbol{D}$, Polar plot of an example 0N OS RGC's response to moving bar stimuli (1000 $\mu \mathrm{m} / \mathrm{s}, 12$ directions) with responses along preferred and null orientations. Direction of bar movement is shown along with the responses. Error bars indicate SEM across three trials in each direction. $\boldsymbol{E}$, Population average normalized orientation tuning curve (see Materials and Methods). Responses were aligned to $0^{\circ}$ representing their peak selectivity. Error bars indicate SEM across cells $(n=60)$. $\boldsymbol{F}$, Population average tuning curve for moving bars aligned as in $\boldsymbol{E}$. Error bars indicate SEM across cells $(n=21)$. G, Histogram of OSI of ON OS $(n=60)$ and non-OS RGCs $(n=86)$ as identified by their light-step response profile. Dotted line indicates $\mathrm{OSI}=0.2$. Error bars indicate SEM.
After locating the center of the RF at a resolution of $20 \mu \mathrm{m}$ (see Materials and Methods), we first investigated orientation selectivity by presenting flashed light bars $(50 \times 800 \mu \mathrm{m})$ presented across the RF center at 12 different orientations. The newly identified ON-sustained RGCs responded preferentially to bars at particular orientations (Fig. 1C), so we will henceforth refer to these cells as ON OS RGCs. Orientation selectivity was also apparent in the responses of ON OS RGCs to moving bars $(50 \times 600$ $\mu \mathrm{m}$ at $1 \mathrm{~mm} / \mathrm{s}$ ) passing through the RF center and selectivity followed the direction of motion (Fig. 1D). OSI was computed as the vector sum of the spike responses to the flashed bar stimuli (Piscopo et al., 2013; see Materials and Methods). Population average response profiles for the flashed and moving bar stimuli are shown in Figure 1, E and F. ON OS RGCs also responded selectively to the orientation of a drifting grating pattern with selectivity following the orientation of the bars (data not shown).

Unlike the response to a circular spot, which included the characteristic pause (Fig. $2 A, C$ ), responses to flashed bars lacked this feature (Fig. $2 B, D$ ). For circular spots, the temporal dynamics of the responses of ON OS RGCs depended on spot size. The initial transient component of the response showed more surround suppression than the sustained component after the pause (Fig. 2E). The unique temporal dynamics of the light response were used to target ON OS RGCs and they provided a classification scheme for ON OS RGCs that was independent of their OS. Based on this classification (Fig. 1B), ON OS RGCs exhibited significantly larger OSIs compared with other ON and ON-OFF RGCs (Fig. 1G, two-sample Kolmogorov-Smirnov test, $p<$ $\left.10^{-23}\right)$. Ninety-three percent $(56 / 60)$ of recorded RGCs matching the light-step response profile of ON OS RGCs had an OSI $>0.2 .10 \%$ (9/86) of ON and ON-OFF RGCs with different lightstep response profiles exceeded this OSI threshold.

Do ON OS RGCs prefer particular orientations in visual space (as has been shown for direction-selective RGCs and OS RGCs in rabbit (Levick, 1967; Oyster and Barlow, 1967; He et al., 1998; Venkataramani and Taylor, 2010) or are all orientations represented as in visual cortex (Hubel and Wiesel, 1974; Blasdel and Salama, 1986; Weliky et al., 1996; Yacoub et al., 2008)? We measured the preferred orientations of ON OS RGCs in retinas in which we had marked the cardinal axes during dissection (Wei et al., 2010; see Materials and Methods). We found two separate populations of ON OS RGCs, which preferred either horizontal (nasal-temporal) or vertical (dorsoventral) cardinal orientations (Fig. 3A). Preferred orientations showed a clear bimodal distribution (Hartigan's dip test, $p<0.001, n=48$ cells). A position map of horizontal and vertical ON OS RGCs averaged across 27 preparations showed no evidence for a bias in the representation of the two axes across visual space (Fig. 3B, two-sample Kolmogorov-Smirnov test, $p=0.66$ for nasal-temporal axis; $p=0.16$ for dorsoventral axis). Both horizontal and vertical OS cells had similar OSI distributions (Fig. 3C, two-sample KolmogorovSmirnov test, $p=0.29$ ), and we observed no differences in their light-step response (two-sample Kolmogorov-Smirnov test, $p=$ 0.86 for peak transient firing rates and $p=0.62$ for peak sustained firing rates). Together, these results identify a new functional RGC class: ON OS RGCs. Like ON-OFF DS RGCs, ON OS RGCs share light response characteristics but can be subdivided into horizontal (ON hOS RGC) and vertical (ON vOS RGC) types based on orientation preference.

\section{Morphology of ON OS RGCs}

In addition to direction preference, some of the subtypes of ONOFF DS RGCs differ in morphological properties. Dendritic 
A

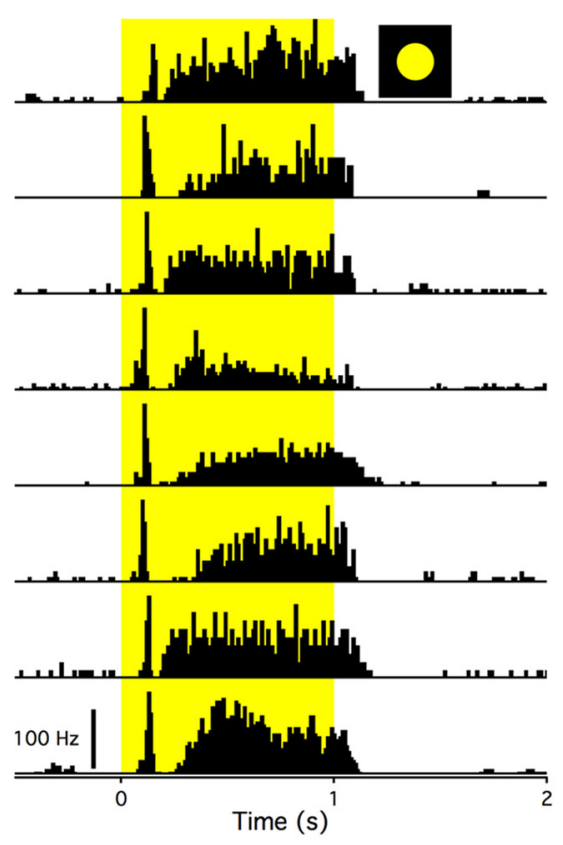

C

E
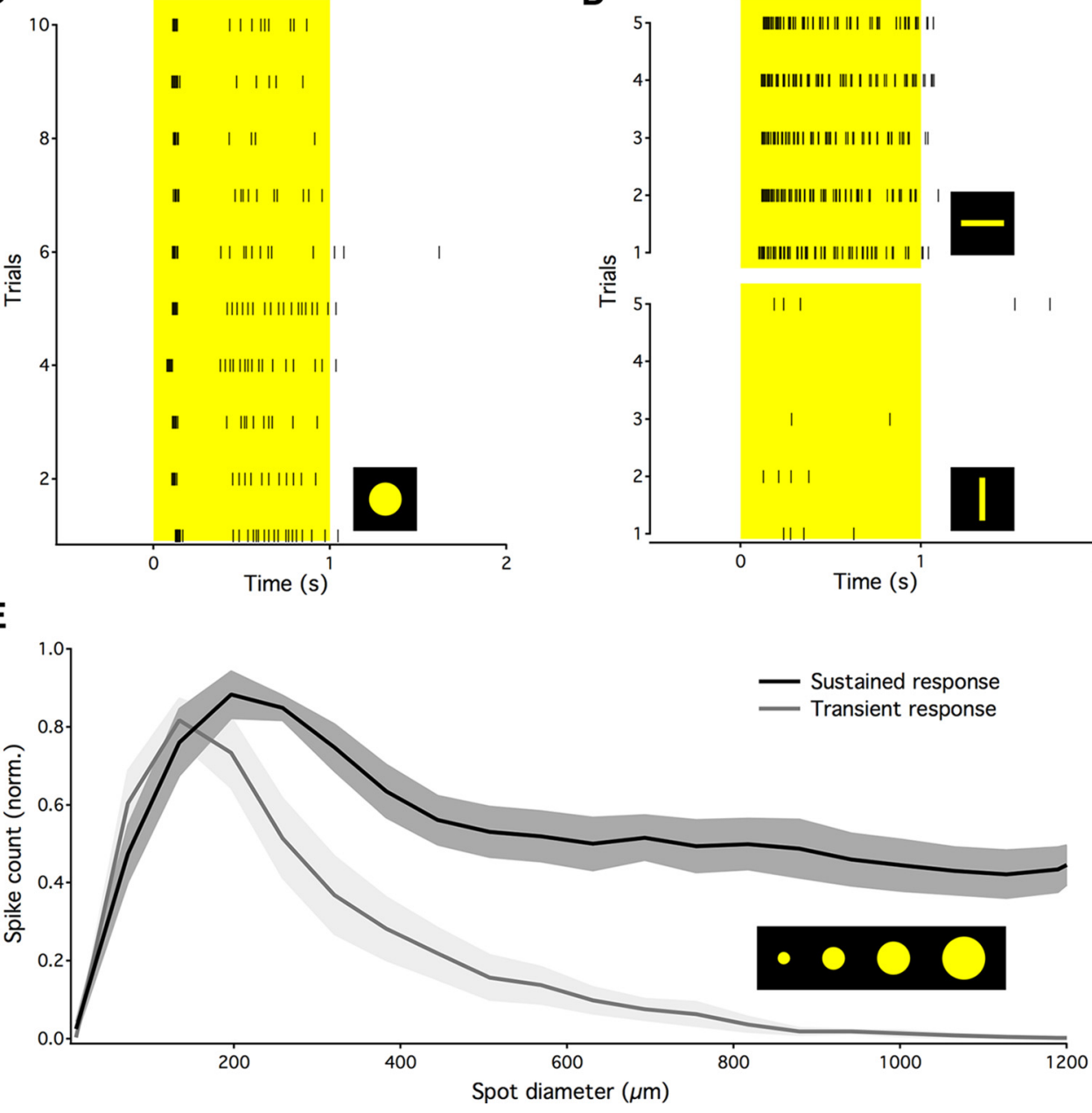

B

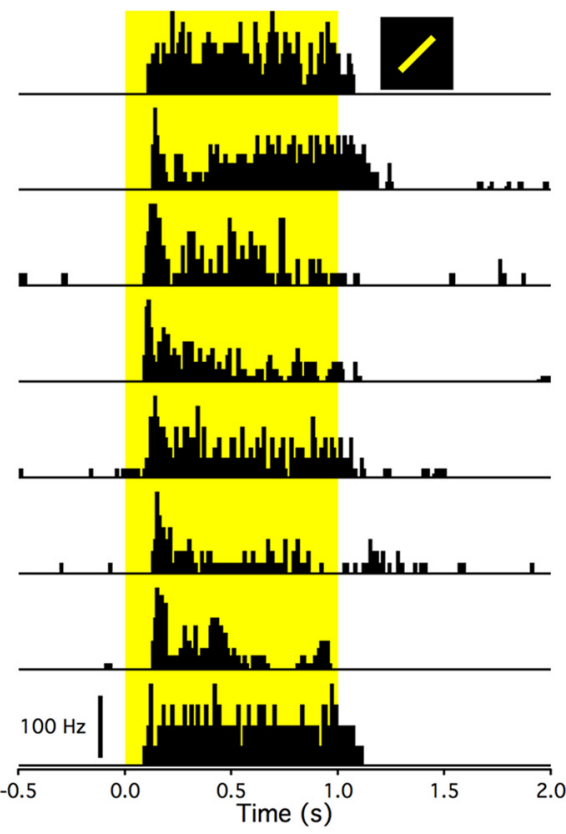

D

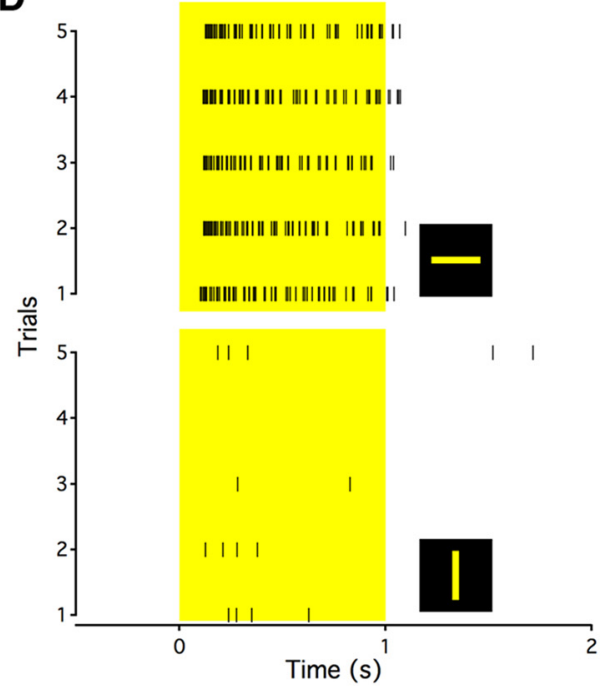

Figure 2. Temporal dynamics of light responses of ON OS RGCS. A Peristimulus time histograms (PSTHs) of light-step responses of 8 representative 0N 0SRGCS. PSTHs are calculated across 10 trials for each cell. Yellow rectangle indicates period of light stimulus. $\boldsymbol{B}$, PSTHs of responses to a flashed bar along preferred orientation for each of the eight $0 \mathrm{~N}$ 0S RGCs in $\boldsymbol{A}$. PSTHs are calculated across five trials for each cell. C, Raster plots of responses of a single ON OS RGC to $1 \mathrm{~s}$ flashes of $200 \mu \mathrm{m}$ diameter circular light spot. $\boldsymbol{D}$, Raster plots of responses of the same cell as in $\boldsymbol{C}$ to bars flashed along preferred (top) and null (bottom) orientations. $E$, Spike count in the transient and sustained portions the light response of ON OS RGCS ( $n=8$ ) to spots of varying diameters. Responses are normalized to their maximum for each cell and averaged across cells. Shaded regions indicate SEM. For more details, see Materials and Methods. 
A

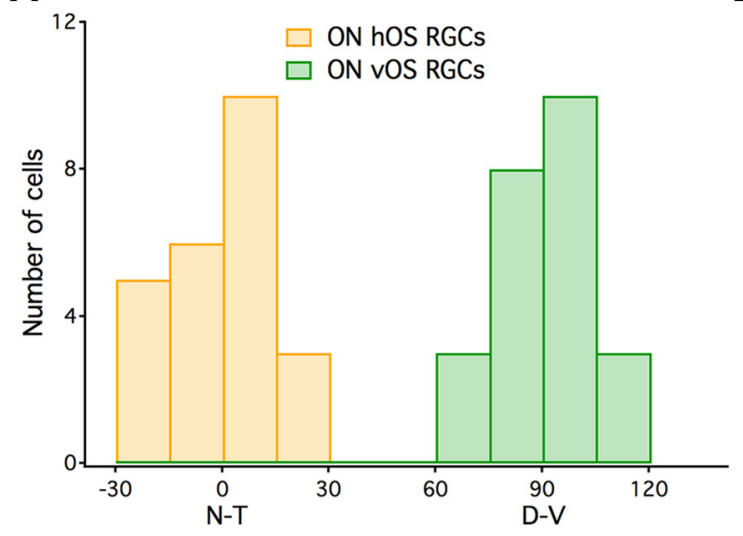

C

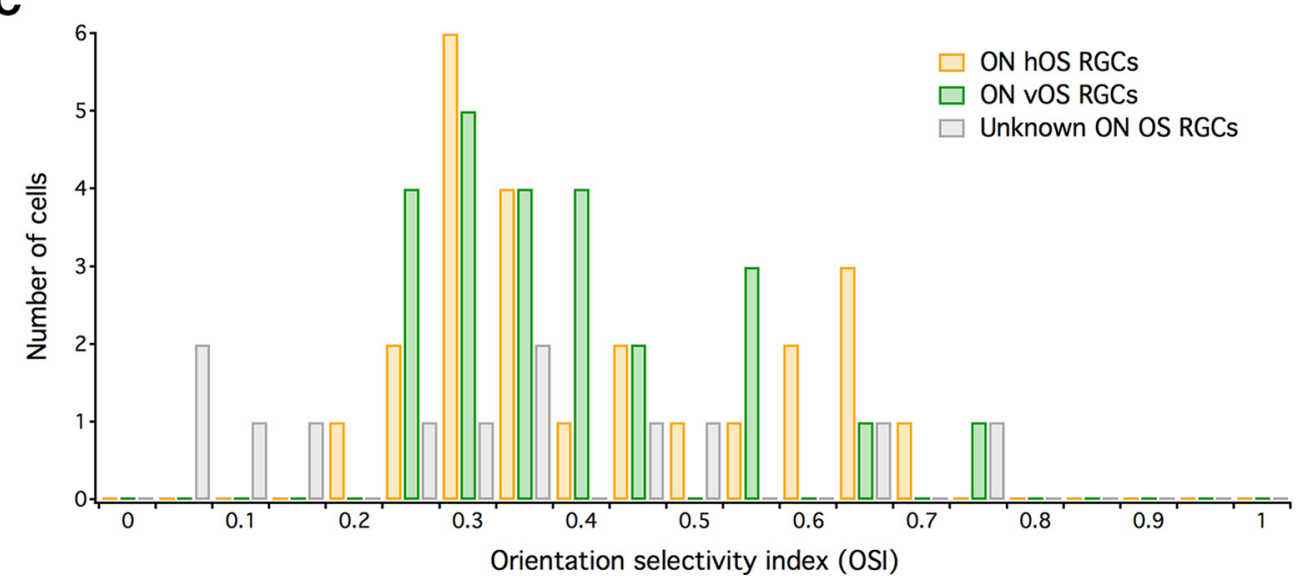

B

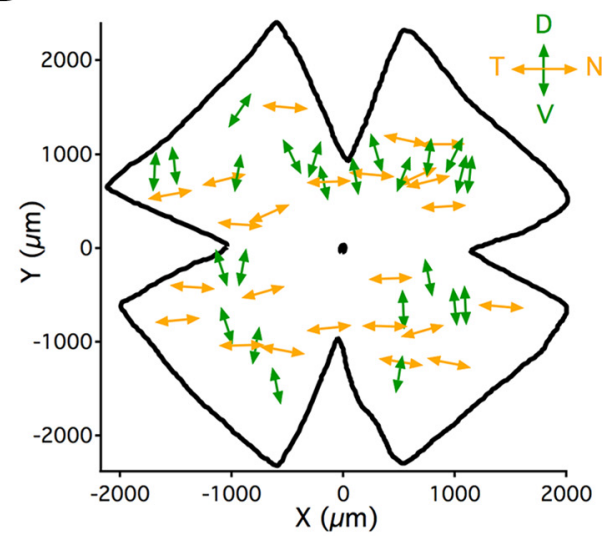



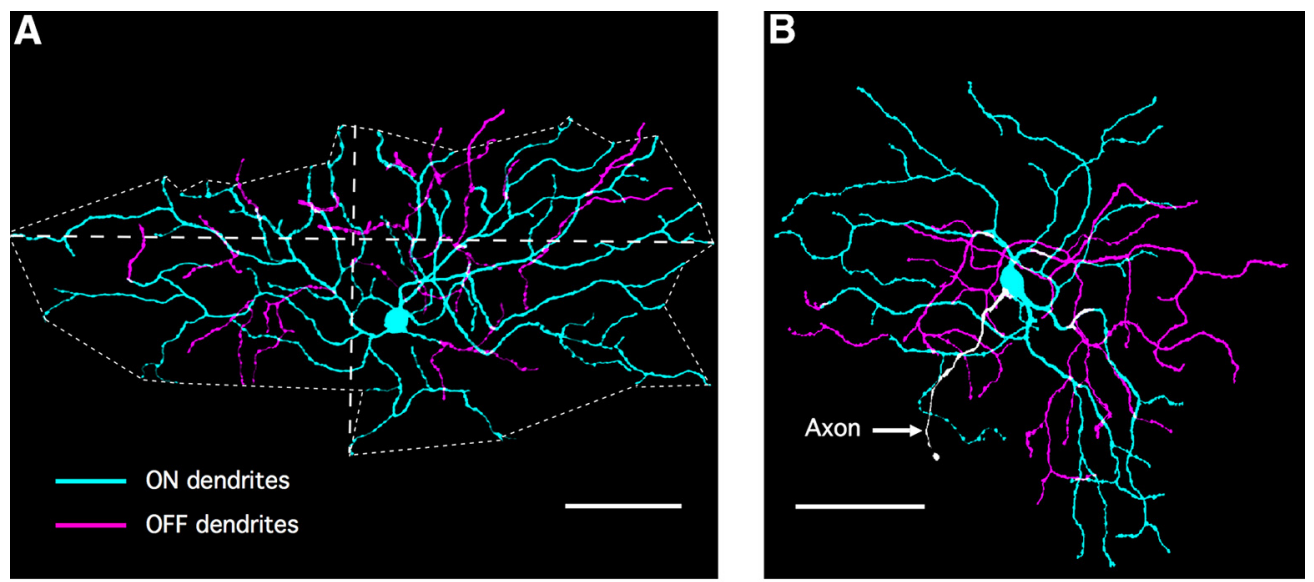

\section{C}

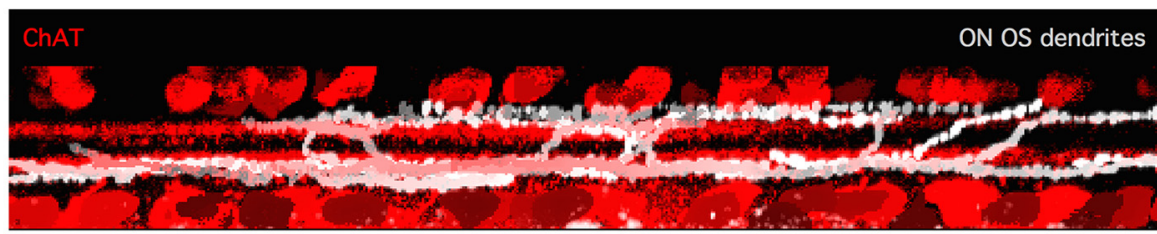

D

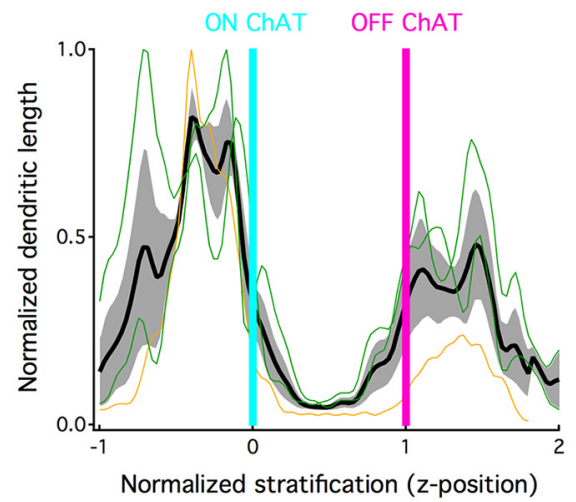

$\mathbf{F}$

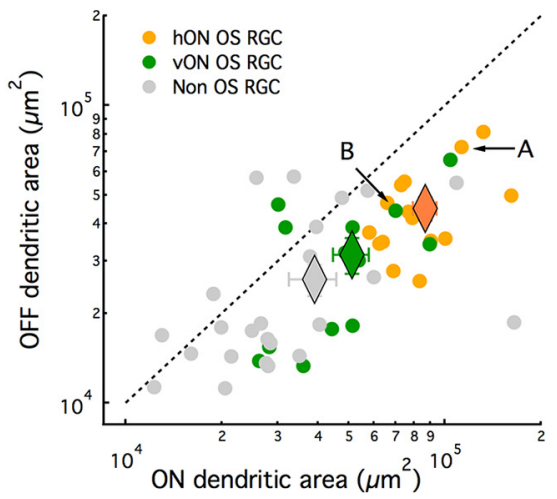

E

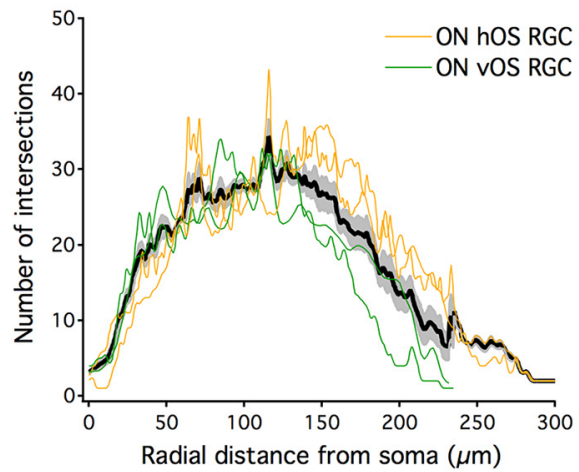

G

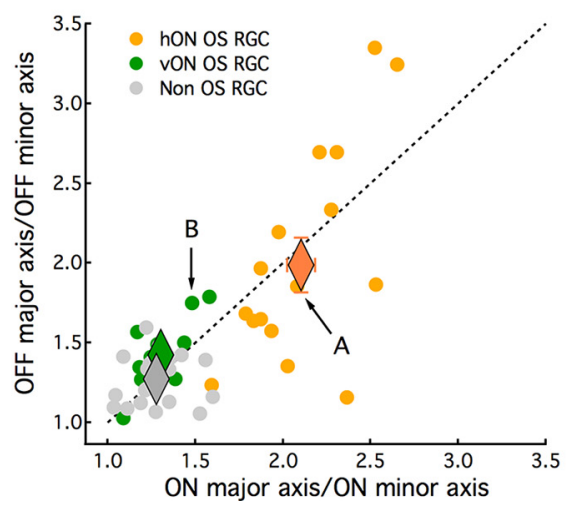

Figure 4. Dendritic morphology of ON OS RGCS. $\boldsymbol{A}, \boldsymbol{B}$, Dendritic morphologies of horizontal ON OS RGC ( $\boldsymbol{A})$ and vertical ON OS RGC (B). Dendrites in ON and OFF sublaminae of the IPL are colored in cyan and magenta, respectively. Major and minor axes and polygon fit for ON dendrites are shown as dotted lines. C, Stratification of ON OS cell dendrites relative to ChAT bands. D, Z-profiles of ON OS dendritic arbor stratification. Orange and green lines indicate profiles of individual ON hOS and ON vOS cells, respectively. Black line represents mean. Cyan and magenta lines indicate $0 \mathrm{~N}$ and OFF starburst planes respectively. The inner nuclear layer (INL) is located to the right and the ganglion cell layer (GCL) is located to the left. Shaded region indicates SEM across three cells (one ON hOS and two ON vOS). E, Sholl analysis of ON OS RGCS. Orange and green lines indicate radial profiles of individual ON hOS and ON vOS cells, respectively. Black line represents mean. Shaded region indicates SEM across four cells (two ON hOS and two ON vOS). $F$, Dendritic field areas of OFF arbors plotted against dendritic field areas of ON arbors for ON OS RGCS ( $n=29)$ and non-OS RGCS $(n=$ 25). Dotted line indicates unity. G, OFF dendritic axes ratio plotted against ON dendritic axis ratio for ON OS RGCS $(n=29)$ and non-OS RGCS $(n=25)$. Dotted line indicates unity. Horizontal ON OS $\operatorname{RGCS}(n=16)$ have a significantly higher axes ratio compared with vertical ON OS $(n=13)$ and non-OS RGCS (two-sample Kolmogorov-Smirnov test, $0 \mathrm{~N}$ dendrites: $p<10^{-6}$ for $0 \mathrm{~N}$ hOS vs $0 \mathrm{~N}$ vOS, $p<10^{-8}$ for $0 \mathrm{~N}$ hOS vs non-OS and $p=0.57$ for $0 \mathrm{~N}$ vOS vs non-OS; OFF dendrites: $p<0.002$ for $0 \mathrm{~N}$ hOS vs $0 \mathrm{~N}$ vOS, $p<10^{-5}$ for $0 \mathrm{~N}$ hOS vs non-OS and $p=0.1$ for $0 \mathrm{~N}$ v0S vs non-OS). Error bars indicate SEM. Cells in $\boldsymbol{A}$ and $\boldsymbol{B}$ are marked with arrows in $\boldsymbol{F}$ and $\boldsymbol{G}$. 
A

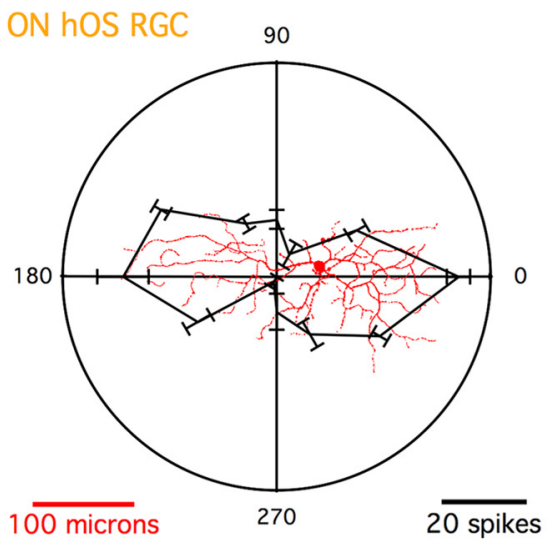

B ON VOS RGC

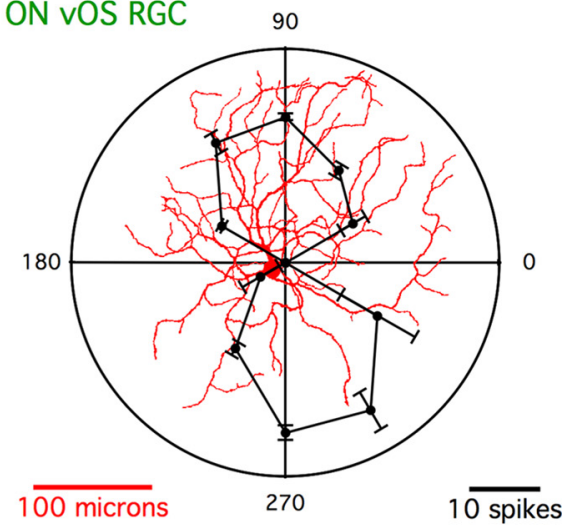

C

90

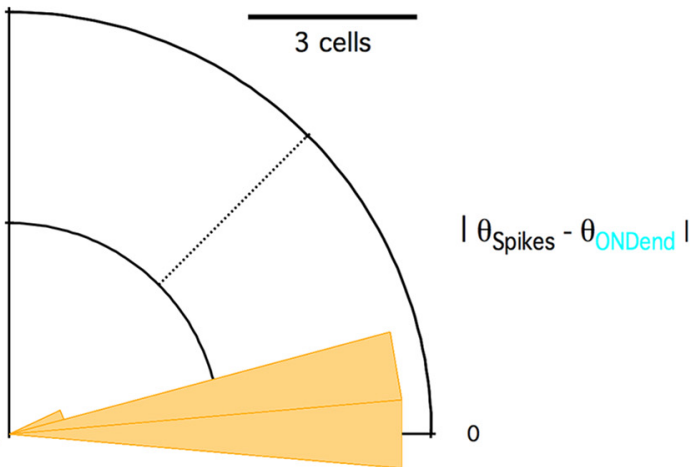

90

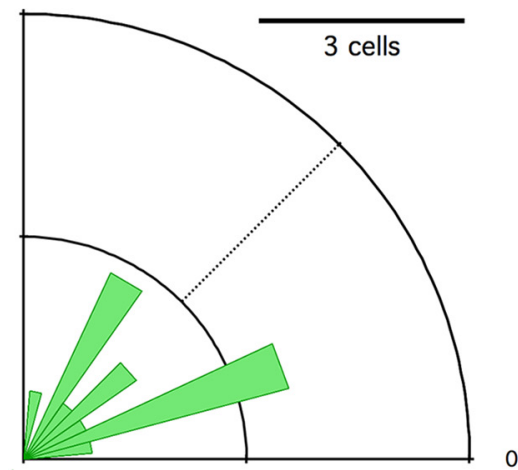

E

90

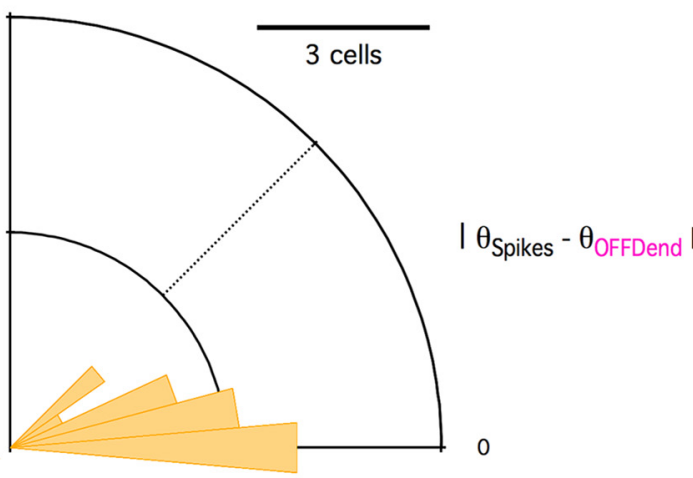

90

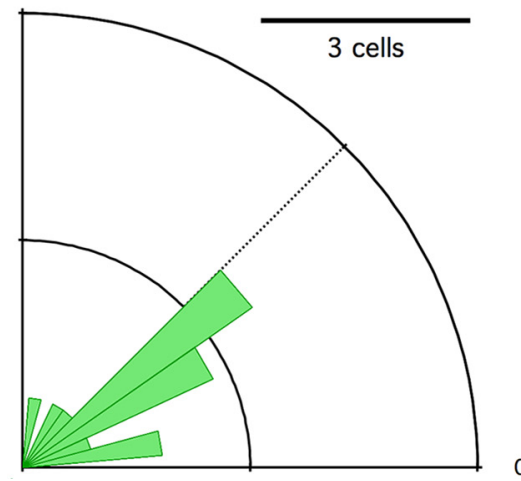

Figure 5. Correlation between dendritic morphology and orientation selectivity. $\boldsymbol{A}, \boldsymbol{B}$, Responses of horizontal ON OS RGC $(\boldsymbol{A})$ and vertical ON 0S RGC (B) to moving bar stimuli. Images of the cells are overlaid on the polar plots. $\boldsymbol{C}, \boldsymbol{D}$, Rose plots of absolute differences between spikes OS angle $\left(\theta_{\text {spikes }}\right)$ and ON dendritic OS angle $\left(\theta_{0 N D e n d}\right)$ of ON h OS RGCs $(n=15 ; \boldsymbol{C})$, and ON vOS RGCs $(n=13$; D). $\boldsymbol{E}, \boldsymbol{F}$, Rose plots of absolute differences between spikes OS angle $\left(\theta_{\text {spikes }}\right)$ and OFF dendritic OS angle $\left(\theta_{\text {OFFDend }}\right)$ of ON h OS RGCS (C) and ON v0S RGCs ( $\left.\boldsymbol{D}\right)$. OS angles were calculated as described in Materials and Methods. Error bars indicate SEM across three trials in each direction.

ger for the ON stratum than the OFF stratum (angle difference $=$ $6.25 \pm 1.41^{\circ}$ and $14.09 \pm 3.37^{\circ}$ for ON and OFF strata, respectively, $n=15$ ). Both these relations were significantly different from a random uniform distribution but not different from each other (two-sample Kolmogorov-Smirnov test, $p<10^{-8}$ and $10^{-4}$ for ON and OFF strata, respectively; paired $t$ test, $p=0.14$ for ON vs OFF strata). ON vOS RGCs had more symmetric dendrites (Fig. 4) and there was no significant relationship between the preferred orientation of spike responses and dendrites in either the ON or OFF strata and a uniform distribution (angle difference $=39.27 \pm 5.75$ and $46.26 \pm 10.42$ for $\mathrm{ON}$ and OFF strata, respectively, $n=13$, two-sample Kolmogorov-Smirnov test, $p=0.27$ for ON strata and $p=0.26$ for OFF strata). The major/minor axis ratio was related to OSI for ON hOS RGCs, but we found no such relationship for ON vOS RGCs (data not shown). Therefore, although asymmetric dendritic morphology is likely to contribute to OS in ON hOS RGCs, ON vOS RGCs are orientation selective despite symmetric morphology.

\section{ON OS RGCs receive OS excitation and inhibition}

Based on previous studies in rabbit, the synaptic framework of OS in the retina has been built upon three main mechanisms: (1) 
uniform excitation received by an oriented dendritic tree, (2) tuned direct GABAergic inhibitory input to RGCs along the null orientation, and (3) tuned presynaptic inhibitory input along the null orientation to bipolar axon terminals resulting in OS excitatory input (Caldwell and Daw, 1978; Amthor et al., 1989; Bloomfield, 1994; Venkataramani and Taylor, 2010). Each of these mechanisms has been identified in different OS RGC populations in rabbit retina, but it remains unclear which exist in the mouse, how they interact, and if there are additional OS mechanisms. We sought to identify the OS inputs to ON OS RGCs with specific emphasis on two new areas of investigation: the contribution of GABAergic and glycinergic circuits in OS inhibition and whether OS excitation is always the result of presynaptic OS inhibition.

To begin to explore the circuit mechanisms of OS in the retina, we measured synaptic conductances in ON OS RGCs using whole-cell voltage-clamp recordings. A light step from darkness elicited an $\mathrm{ON}$ excitatory current with distinct transient and sustained components and both $\mathrm{ON}$ and OFF inhibition (Fig. 6A). It is notable that we measured no excitatory current at light offset despite the bistratified morphology of ON OS RGCs, suggesting that the OFF-stratifying dendrites do not receive excitation from OFF bipolar cells. An OFF stratification with no excitatory input has also been observed in the suppressed-by-contrast RGC (Jacoby et al., 2015).

Both excitatory and inhibitory conductances were orientation selective when probed with flashed bars and, remarkably, preferred orthogonal orientations (Fig. $6 B, C$ ). At the population level, we measured oppositely orientation-tuned excitation and inhibition for ON hOS RGCs, but OS excitation and non-OS inhibition for ON vOS RGCs (Fig. 6D,E). Moving bars gave similar results at the population level (Fig. $6 F, G$ ).

In ON hOS RGCs, the preferred orientation for excitation was well aligned to that of the spike response and inhibition was aligned to the orthogonal (null) orientation (Fig. $7 \mathrm{~A}, \mathrm{C}$ ). Despite untuned inhibition in the population, individual ON vOS RGCs also showed OS excitation and inhibition with OSIs not significantly different from ON hOS RGCs (Fig. $7 E, F$, two-sample Kolmogorov-Smirnov test $p=0.97$ for excitation OSI and $p=$ 0.99 for inhibition OSI). Although excitatory orientation preference for ON vOS RGCs was well aligned to spike responses, inhibition was tuned along apparently random orientations (Fig. $7 B, D)$. We found no statistical difference between our measured distribution of inhibitory tuning preference for $\mathrm{ON}$ vOS RGCs and a uniform distribution ( $p=0.64$, two-sample Kolmogorov-Smirnov test).

\section{Pharmacology of OS conductances}

Amacrine cells provide inhibition (onto RGCs, bipolar cells, and each other) in the inner retina by releasing GABA or glycine and GABAergic starburst amacrine cells are known to play a major role in DS circuits (Euler et al., 2002; Fried et al., 2002; Lee et al., 2010; Wei et al., 2011; Yonehara et al., 2011). To explore the source(s) of the OS conductances that we measured in ON OS RGCs, we bath applied antagonists for subtypes of GABA receptors or for glycine receptors (see Materials and Methods).

Both GABAergic and glycinergic circuits provide inhibition to ON OS RGCs (Fig. 8A,E) and application of antagonists to both receptor types completely abolished inhibition. To determine which of these circuits provides OS inhibition, we blocked them sequentially (in both orders). Surprisingly, OS inhibition persisted in presence of either gabazine or glycine but was eliminated in the presence of both antagonists, suggesting that both GABAe- rgic and glycinergic amacrine cells supply OS inhibition (Fig. $8 C, F, G, H)$. Tetrodotoxin (TTX), $\mathrm{GABA}_{\mathrm{B}}$ and $\mathrm{GABA}_{\mathrm{C}}$ receptor antagonists had no effect on OS inhibition (data not shown).

Bipolar cells relay excitatory information from photoreceptors to RGCs. Receptive fields of bipolar cells are $\sim 50 \mu \mathrm{m}$ in diameter (Berntson and Taylor, 2000; Schwartz et al., 2012). Compared with the spatial scale of ON OS RGC dendrites and our flashed bar stimuli, these cells can be considered as small, nonoriented sources of excitation. Previous reports have indicated that presynaptic inhibition of bipolar cell axon terminals by amacrine cells might lead to OS excitation in RGCs (Caldwell and Daw, 1978; Venkataramani and Taylor, 2010). Excitatory input remained unaffected by a single inhibitory blocker (either gabazine or strychnine), but was significantly amplified in the presence of both drugs (Fig. 8B,E, two-sample KolmogorovSmirnov test). None of the antagonists eliminated OS excitation when applied individually. Surprisingly, OS excitation was not diminished in the presence of both drugs (Fig. $8 D, F, G, H$ ). OS excitation was also unchanged by adding $\mathrm{GABA}_{\mathrm{B}}$ and $\mathrm{GABA}_{\mathrm{C}}$ receptor antagonists to the blocker mixture (data not shown). Consistant with the whole-cell pharmacology, OS spike responses persisted in presence of total inhibitory block (data not shown). In summary, our data show for the first time that both GABAergic and glycinergic amacrine cells contribute to OS inhibition and that the retina has OS excitation that is independent of inhibitory drive.

\section{Discussion}

Our discovery and characterization of ON OS RGCs in mouse retina raises a number of questions both about the mechanisms of OS in the retina and the role of these RGCs in downstream visual processing. Although selective genetic access to ON OS RGCs, which is not presently available, will be critical in answering many of these questions, here, we discuss the following: (1) how our findings relate to past reports of OS RGCs, (2) the relationship between dendritic morphology and direction or orientation selectivity, (3) the origin of OS excitatory and inhibitory conductances in the retina, and (4) the roles and possible interactions between multiple OS pathways in the early visual system.

\section{Previous reports of OS RGCs}

Levick (1967) first reported the existence OS RGCs in rabbit retina. He found both ON and OFF type OS RGCs and these RGCs were selective for either horizontal or vertical orientations of stationary or moving bars. The circuit mechanisms of OS in rabbit RGCs were first studied by Caldwell and Daw (1978), who showed that the $\mathrm{GABA}_{\mathrm{A}}$ and $\mathrm{GABA}_{\mathrm{C}}$ receptor antagonist picrotoxin abolished OS spike responses. This result led them to propose a model in which a circular excitatory receptive field center is flanked by an oriented inhibitory surround. Subsequent work combined intracellular recordings with dye fills of OS amacrine and ganglion cells in rabbit retina and suggested that oriented dendrites could give rise to OS excitation, which could combine with OS inhibition tuned to the orthogonal orientation to enhance selectivity (Amthor et al., 1989; Bloomfield, 1994). Finally, a more recent study used voltage-clamp recordings to show that OS in horizontal and vertical OFF OS RGCs in rabbit relies on presynaptic GABAergic inhibition, but that the two cell types differ in that horizontal OFF OS RGCs receive direct OS inhibition (tuned to the null orientation), whereas vertical OFF OS RGCs are instead influenced by a disinhibitory circuit that reduces tonic inhibition in the preferred orientation (Venkataramani and Taylor, 2010). 
A

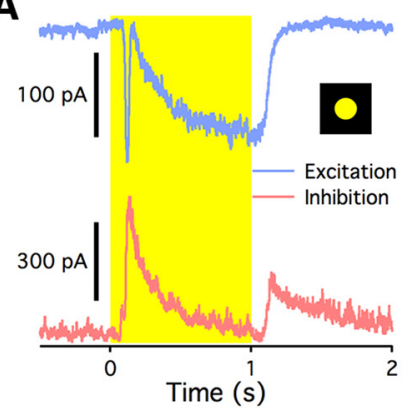

D
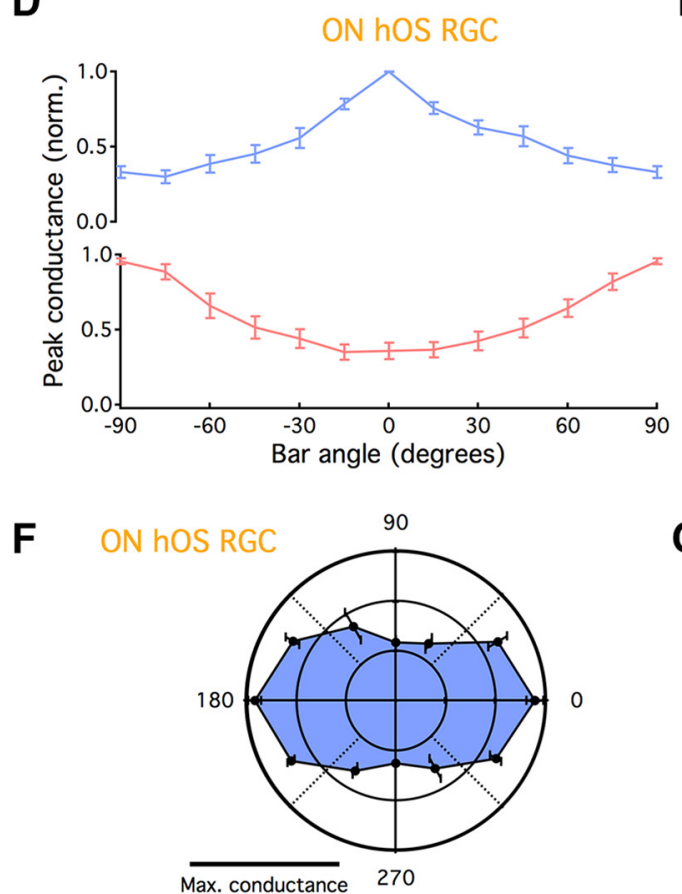

Max conductance 270

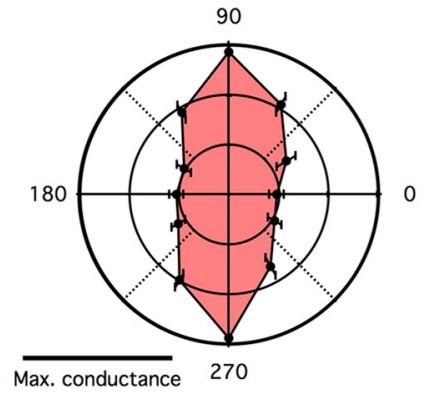

B

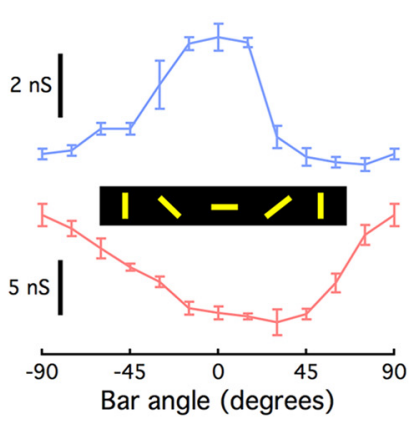

$\mathbf{E}$
C
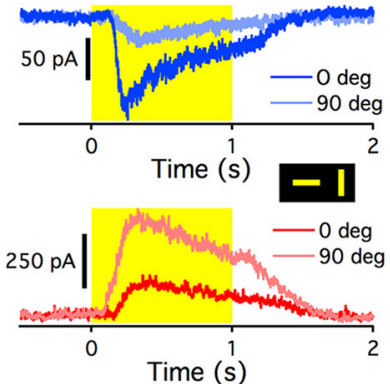

ON vOS RGC
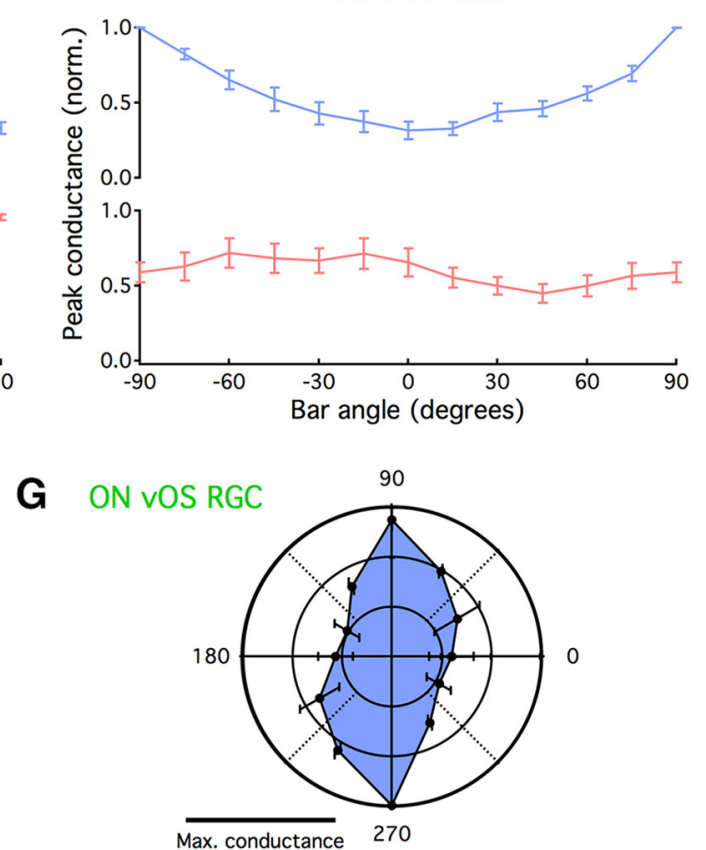

Max. conductance 270

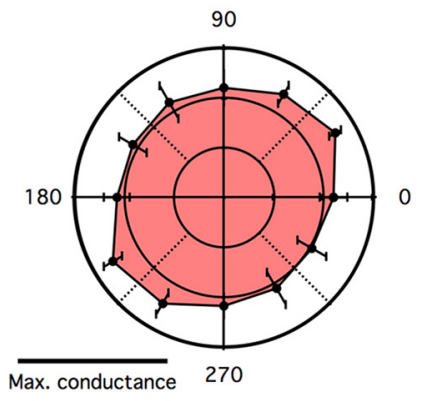

Figure 6. Excitatory and inhibitory synaptic inputs to ON OSRGCS. A, Responses of an ON OSRGC to a $1 \mathrm{~s}$ flash of $200-\mu \mathrm{m}$-diameter circular light spot. Cell voltage clamped at $-60 \mathrm{mV}$, the reversal potential for inhibition (top trace, blue). Cell voltage clamped at $20 \mathrm{mV}$, the reversal potential for excitation (bottom trace, red). Yellow rectangle indicates period of light stimulus. $\boldsymbol{B}$, Responses of ON hOS RGC to flashed bar stimuli (top trace) and excitation (bottom trace) inhibition. Error bars indicate SEM across five trials at each orientation. C, Traces of excitation (top) and inhibition (bottom) at $0^{\circ}$ and $90^{\circ}$ bar orientations for cell in $\boldsymbol{B} . \boldsymbol{D}, \boldsymbol{E}$, Population averaged responses of horizontal $(n=9 ; \boldsymbol{D})$ and vertical $(n=11 ; \boldsymbol{E})$ ON OS RGCs to oriented light bar stimuli (top traces) and excitation (bottom traces) inhibition. Error bars indicate SEM across cells. $\boldsymbol{F}, \boldsymbol{G}$, Population-averaged responses of horizontal $(n=3 ; \boldsymbol{F})$ and vertical $(n=3 ; \boldsymbol{G})$ ON OS RGCs to moving bar stimuli; excitatory currents (top traces), inhibitory currents (bottom traces). Error bars indicate SEM across cells.

Despite this body of work on OS RGCs in rabbit, no previous study has identified a distinct, OS RGC type in the mouse. A recent study identified several functional RGC clusters showing OS, but did not assign these clusters to putative RGC types (Baden et al., 2016). OS RGCs are notably absent from a large-scale physiological classification of mouse RGCs (Farrow and Masland, 2011) and no cell type with consistently oriented dendrites (other than the OFF direction-selective JAM-B RGC (Kim et al., 2008) was found in two large mor- phological RGC classifications (Völgyi et al., 2009; Sümbül et al., 2014). Zhao et al. (2013) found OS responses in multielectrode array recordings from mouse retina, but were not able to attribute the responses to a particular RGC type or to discount the possibility that some of the recorded units were displaced, spiking amacrine cells.

We report horizontal and vertical ON OS RGCs in the mouse, but remain agnostic about whether the mouse retina also contains OFF OS RGCs. Rabbit OS RGCs with both symmetric and 
A

90

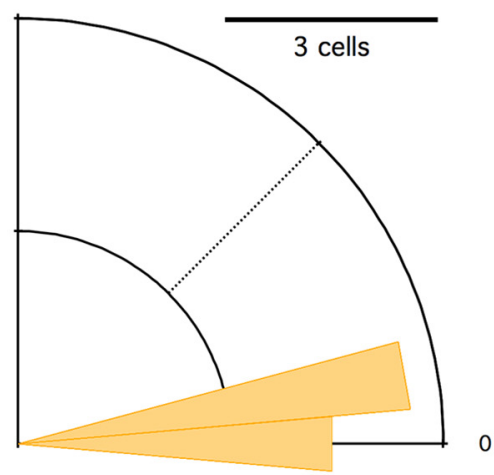

C

90

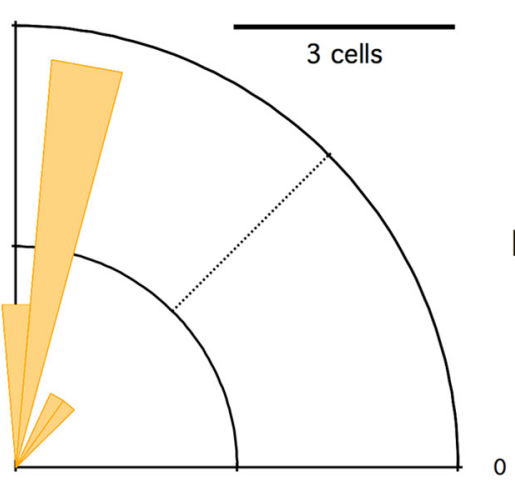

E

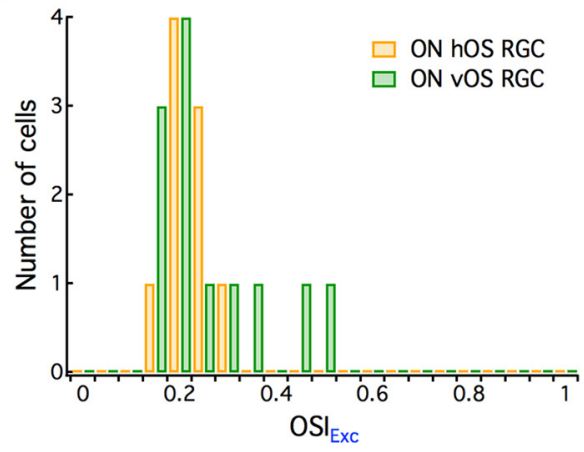

B

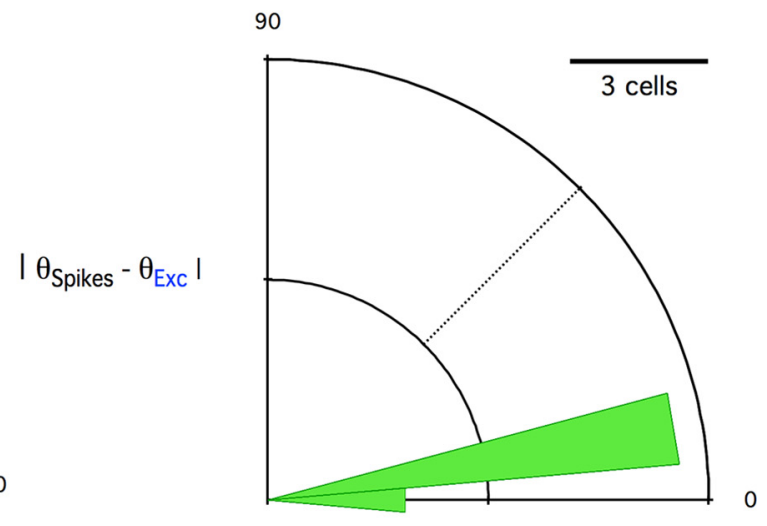

D

90

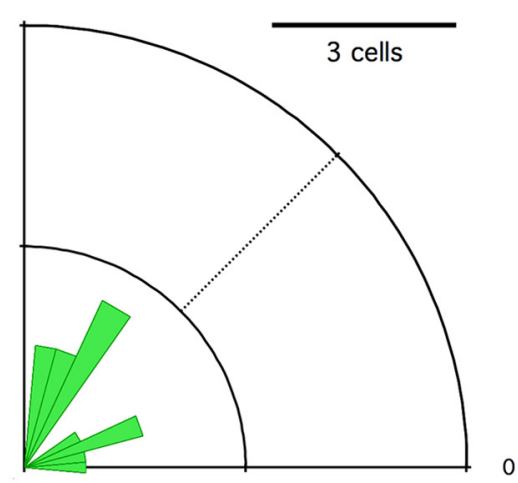

$\mathbf{F}$

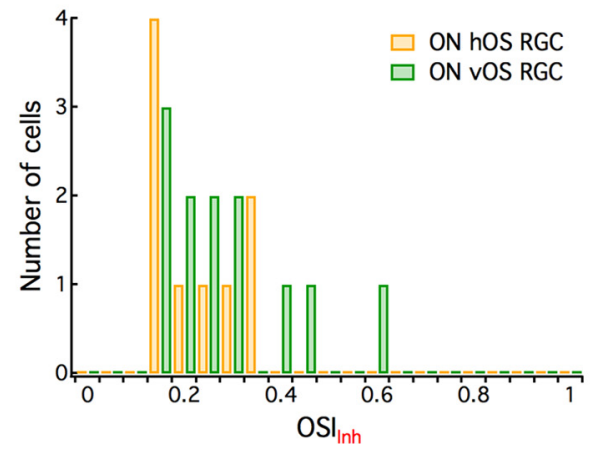

Figure 7. Correlation between synaptic inputs and orientation tuning. $\boldsymbol{A}, \boldsymbol{B}$, Rose plots of absolute differences between spikes $0 \mathrm{~S}$ angle $\left(\theta_{\text {spikes }}\right)$ and excitation $0 \mathrm{~S}$ angle $\left(\theta_{\text {Exc }}\right)$ of $0 \mathrm{~N}$ hOS RGCS $(n=9 ; \boldsymbol{A})$ and ON vOS RGCS $(n=12 ; \boldsymbol{B})$. C, $\boldsymbol{D}$, Rose plots of absolute differences between spikes OS angle $\left(\theta_{\text {spikes }}\right)$ and inhibition OS angle $\left(\theta_{\mathrm{Inh}}\right)$ of ON hOS RGCS $(\boldsymbol{C})$ and $0 \mathrm{~N}$ v0S RGCS $(\boldsymbol{D}) . \boldsymbol{E}, \boldsymbol{F}$, OSI histograms for excitatory and inhibitory inputs received by horizontal and vertical ON OS RGCs. OS angles were calculated as described in Materials and Methods.

asymmetric dendritic morphology have been reported. We also found both morphological types, but we showed a clear relationship between morphological type and orientation preference, with ON hOS RGCs having asymmetric dendrites and ON vOS RGCs having symmetric dendrites (Fig. 5). Our pharmacology experiments also both agree with aspects of the rabbit data and reveal new OS circuit components. Although we found a role for GABAergic inhibition in the OS computation, consistent with previous work, we also identified novel sources of OS information in a glycinergic conductance and in an excitatory conductance that was not controlled by presynaptic inhibition (Fig. 8). The mechanistic implications of these novel OS conductances are discussed below.

\section{Relationship between dendritic morphology and DS/OS computation}

The correspondence between the dendritic morphology of RGCs in the plane of the IPL and their receptive fields is well documented (Kier et al., 1995). The simplest mechanism by which a RGC could achieve OS is by developing asymmetric dendrites so that a greater number of bipolar cells making excitatory synapses on the RGC are activated for stimuli in the preferred orientation than for stimuli in the null orientation. Both symmetric and asymmetric morphologies have been reported among rabbit OS RGCs and OS amacrine cells and asymmetric morphologies have shown a correspondence with orientation preference in some studies (Amthor et al., 1989; Bloomfield, 1994; Murphy-Baum 
A

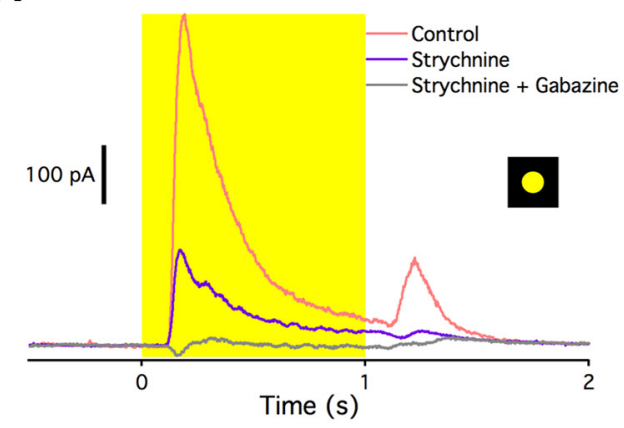

C

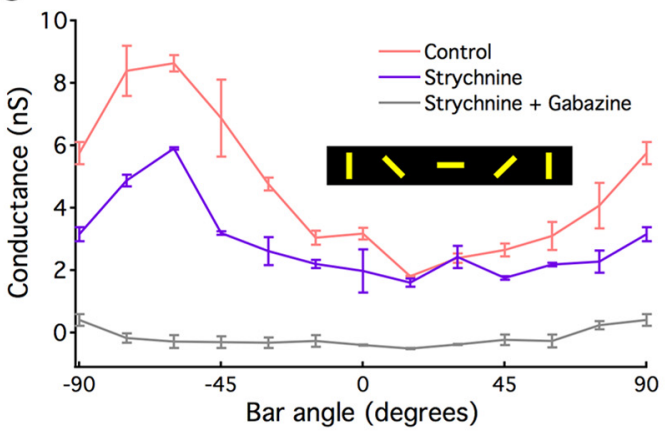

E
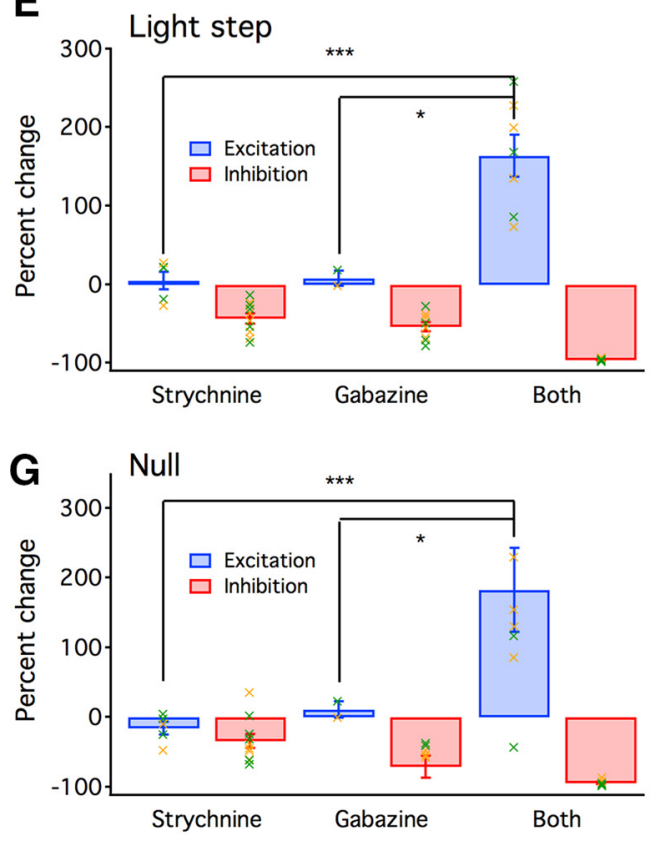

B

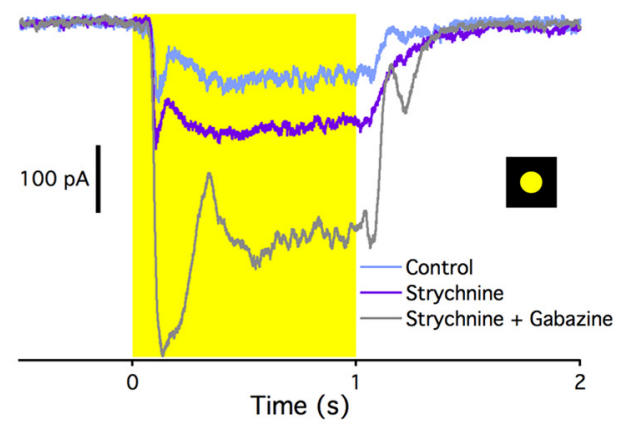

D

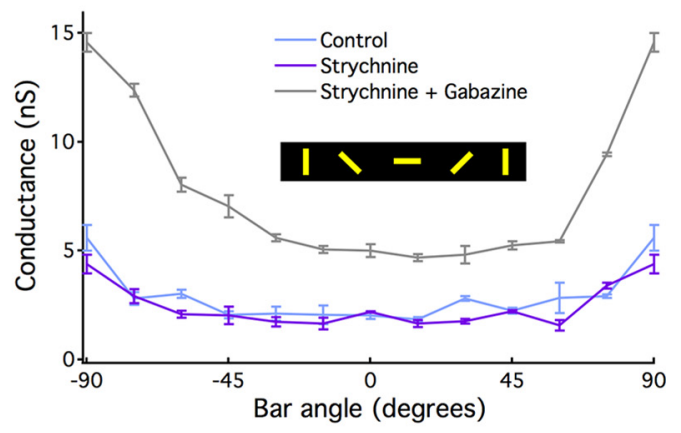

F

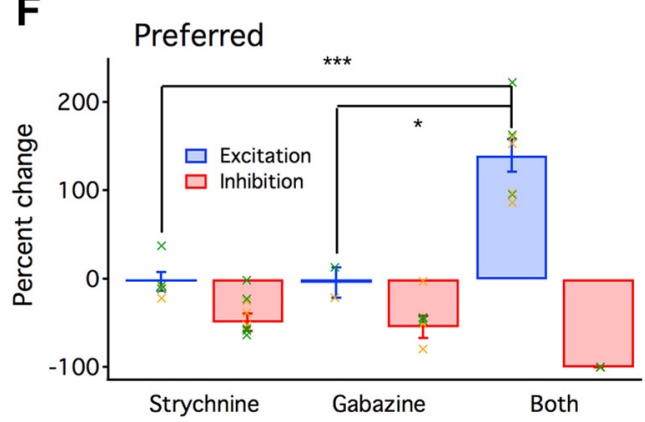

H

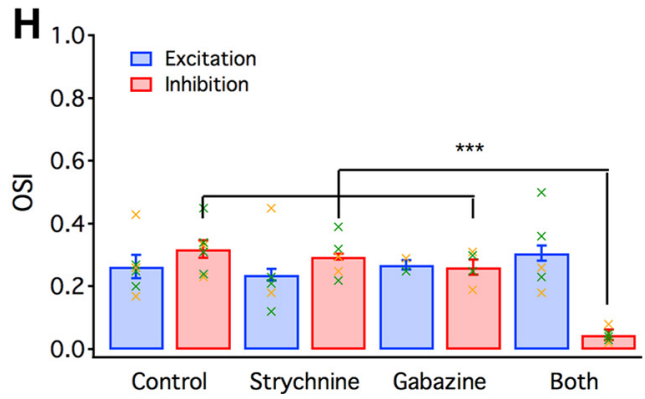

Figure 8. Pharmacological characterization of synaptic inputs. $\boldsymbol{A}, \boldsymbol{B}$, Effect of GABA and glycine antagonists on light-step responses of ON OS RGCS. $\boldsymbol{A}$, Inhibition, $\boldsymbol{B}$, Excitation. Yellow rectangle indicates period of light stimulus. C, D, Flashed bar responses of a vertical ON OS RGC in presence of inhibitory blockers. C, Inhibition, D, Excitation. Error bars indicate SEM across five trials at each orientation. $\boldsymbol{E}-\boldsymbol{G}$, Percentage change in excitatory and inhibitory peak amplitudes in inhibitory antagonists for light step $(\boldsymbol{E})$, preferred orientation $(\boldsymbol{F})$, and null orientation $(\boldsymbol{G})$. Orange and green crosses indicate data from individual ON hOS and ON vOS cells, respectively. $\boldsymbol{H}$, Effect of inhibitory blockers on 0 SI of excitatory and inhibitory inputs. Error bars indicate SEM $(n=4$ for strychnine, $n=4$ for gabazine, and $n=8$ for both drugs). Orange and green crosses indicate data from individual ON hOS and ON vOS cells, respectively. ${ }^{* *} p<0.001,{ }^{*} p<0.05$.

and Taylor, 2015), but not in others (Venkataramani and Taylor, 2010). Asymmetric dendritic morphology has also been implicated in the computation of direction selectivity both within dendritic branches of starburst amacrine cells (Lee and Zhou, 2006; Kim et al., 2014) and in some types of DS RGCS (Kim et al., 2008; Trenholm et al., 2011), but another study reported asymmetric morphology in DS RGCs with no correspondence to direction preference (Kay et al., 2011).
We found that ON hOS RGCs have asymmetric dendrites aligned with the orientation preference of the response (Fig. 5). Although this morphology likely contributes to the OS computation, this simple mechanism is an incomplete explanation for the selectivity of ON OS RGCs because ON vOS RGCs receive OS excitation (Fig. 5) despite symmetric dendrites (Fig. 4) and both ON OS RGC types receive OS inhibition (Fig. 6) that is not aligned to the orientation of the dendrites (Fig. 7). 


\section{Origin of OS conductances in the retina}

Both excitatory and inhibitory conductances in ON OS RGCs were orientation selective. OS inhibition was resistant to either GABA or glycine receptor antagonists applied alone-a combination of both antagonists eliminated all inhibition - whereas OS excitation was resistant to all inhibitory receptor blockers tested (Fig. 8) and OS spike responses persisted in complete inhibitory block (data not shown). These results suggest that multiple OS pathways converge onto ON OS RGCs.

OS inhibition is likely carried by a combination of glycinergic and GABAergic amacrine cells, but it is unclear whether the amacrine cells themselves are OS or if OS arises though selective connectivity with particular neurites of the amacrine cells, as is the case in the starburst amacrine cell to ON-OFF DS RGC circuit (Briggman et al., 2011). The origin of OS excitation remains more elusive because it was resistant to a full inhibitory block even in ON vOS RGCs, which have symmetric dendrites. We can envision three circuit configurations to account for OS excitation: (1) one of the ON bipolar cell types carries OS information, presumably type 8 or type 9 given the stratification profile of ON OS RGCs (Wässle et al., 2009; Helmstaedter et al., 2013, Fig. 4C,D); (2) bipolar cells themselves are not OS, but selective connectivity with the dendrites of ON OS RGCs (more numerous or stronger excitatory synapses along the preferred orientation) endows the postsynaptic cell with OS; or (3) OS excitation is not carried by a bipolar cell but instead by an OS, glutamate-releasing amacrine cell. The existence of such excitatory connections from amacrine cells has been shown recently in a different retinal circuit (Lee et al., 2014).

Our voltage-clamp recordings provided clear evidence for OS conductances in ON OS RGCs, but we cannot rule out a role for active conductances in enhancing OS. Dendritic spikes have been shown to play a role in the DS computation in ON-OFF DS RGCs (Oesch et al., 2005).

\section{Multiple OS pathways in the early visual system}

Orientation selectivity is a major response property of visual cortex across mammalian species (Hubel and Wiesel, 1962, 1968; Chapman et al., 1991; Niell and Stryker, 2008) and there is substantial evidence in favor of Hubel and Wiesel's model of OS emerging from selective wiring from LGN to V1, including in mouse (Lien and Scanziani, 2013). However, a body of recent evidence has shown that this is not the only OS pathway in the mouse visual system. OS responses have been recorded in both LGN (Marshel et al., 2012; Piscopo et al., 2013; Zhao et al., 2013) and SC (Wang et al., 2010; Ahmadlou and Heimel, 2015; Feinberg and Meister, 2015) in conditions designed to minimize the influence of cortical feedback. Recently, OS cells have also been reported in the koniocellular layers of primate LGN (Cheong et al., 2013). Therefore, separate OS pathways exist in parallel in the early visual system. A similar picture has emerged for DS pathways in the mouse, in which retinal DS information is transmitted to a substructure within dorsal LGN and then onto the superficial layers of cortex (Cruz-Martín et al., 2014). This pathway coexists with more traditional DS circuits in the input layers of cortex (Livingstone, 1998; Atallah et al., 2012; Lee et al., 2012).

Do the different OS pathways subserve different behaviors or perceptions? One clue lies in the distribution of orientation preferences. OS cells in cortex represent all orientations in a fairly uniform distribution (Hubel and Wiesel, 1974; Blasdel and Salama, 1986) and this representation has been linked to the perception of continuous edges defining object boundaries (Swindale et al., 2000). OS cells in LGN may be tuned to cardinal orientations (Marshel et al., 2012; Piscopo et al., 2013), as we found in the retina (but see Zhao et al., 2013). In SC, preferred orientation appears to be linked to retinotopic position, perhaps to represent optic flow (Ahmadlou and Heimel, 2015). Future work will be needed to determine whether these different representations of orientation information are indeed tied to different behaviors and if they interact given that LGN, SC, and V1 are interconnected structures (Bickford et al., 2015). Marshel et al. (2012) proposed selective connectivity of oppositely tuned ONOFF DS RGCs as the source of cardinal OS in LGN. The two cardinal ON OS RGCs that we identified here offer a more parsimonious explanation for cardinal OS in LGN, but tracing studies will be needed to determine their projection patterns within the brain and the possible transformations of OS information in postsynaptic cells.

\section{References}

Ahmadlou M, Heimel JA (2015) Preference for concentric orientations in the mouse superior colliculus. Nat Commun 6:6773. CrossRef Medline

Amthor FR, Takahashi ES, Oyster CW (1989) Morphologies of rabbit retinal ganglion cells with complex receptive fields. J Comp Neurol 280: 97-121. CrossRef Medline

Atallah BV, Bruns W, Carandini M, Scanziani M (2012) Parvalbuminexpressing interneurons linearly transform cortical responses to visual stimuli. Neuron 73:159-170. CrossRef Medline

Baden T, Berens P, Franke K, Román Rosón M, Bethge M, Euler T (2016) The functional diversity of retinal ganglion cells in the mouse. Nature 529:345-350. CrossRef Medline

Berntson A, Taylor WR (2000) Response characteristics and receptive field widths of on-bipolar cells in the mouse retina. J Physiol 524:879-889. CrossRef Medline

Bickford ME, Zhou N, Krahe TE, Govindaiah G, Guido W (2015) Retinal and tectal "driver-like" inputs converge in the shell of the mouse dorsal lateral geniculate nucleus. J Neurosci 35:10523-10534. CrossRef Medline

Blasdel GG, Salama G (1986) Voltage-sensitive dyes reveal a modular organization in monkey striate cortex. Nature 321:579-585. CrossRef Medline

Bloomfield SA (1994) Orientation-sensitive amacrine and ganglion cells in the rabbit retina. J Neurophysiol 71:1672-1691. Medline

Briggman KL, Helmstaedter M, Denk W (2011) Wiring specificity in the direction-selectivity circuit of the retina. Nature 471:183-188. CrossRef Medline

Caldwell JH, Daw NW (1978) Effects of picrotoxin and strychnine on rabbit retinal ganglion cells: changes in centre surround receptive fields. J Physiol 276:299-310. CrossRef Medline

Chapman B, Zahs KR, Stryker MP (1991) Relation of cortical cell orientation selectivity to alignment of receptive fields of the geniculocortical afferents that arborize within a single orientation column in ferret visual cortex. J Neurosci 11:1347-1358. Medline

Chen H, Liu X, Tian N (2014) Subtype-dependent postnatal development of direction- and orientation-selective retinal ganglion cells in mice. J Neurophysiol 112:2092-2101. CrossRef Medline

Cheong SK, Tailby C, Solomon SG, Martin PR (2013) Cortical-like receptive fields in the lateral geniculate nucleus of marmoset monkeys. J Neurosci 33:6864-6876. CrossRef Medline

Cruz-Martín A, El-Danaf RN, Osakada F, Sriram B, Dhande OS, Nguyen PL, Callaway EM, Ghosh A, Huberman AD (2014) A dedicated circuit links direction-selective retinal ganglion cells to the primary visual cortex. Nature 507:358-361. CrossRef Medline

Euler T, Detwiler PB, Denk W (2002) Directionally selective calcium signals in dendrites of starburst amacrine cells. Nature 418:845-852. CrossRef Medline

Farrow K, Masland RH (2011) Physiological clustering of visual channels in the mouse retina. J Neurophysiol 105:1516-1530. CrossRef Medline

Feinberg EH, Meister M (2015) Orientation columns in the mouse superior colliculus. Nature 519:229-232. Medline

Fried SI, Münch TA, Werblin FS (2002) Mechanisms and circuitry underlying directional selectivity in the retina. Nature 420:411-414. CrossRef Medline

He S, Levick WR, Vaney DI (1998) Distinguishing direction selectivity from 
orientation selectivity in the rabbit retina. Vis Neurosci 15:439-447. Medline

Helmstaedter M, Briggman KL, Turaga SC, Jain V, Seung HS, Denk W (2013) Connectomic reconstruction of the inner plexiform layer in the mouse retina. Nature 500:168-174. CrossRef Medline

Hubel DH, Wiesel TN (1962) Receptive fields, binocular interaction and functional architecture in the cat's visual cortex. J Physiol 160:106-154. CrossRef Medline

Hubel DH, Wiesel TN (1968) Receptive fields and functional architecture of monkey striate cortex. J Physiol 195:215-243. CrossRef Medline

Hubel DH, Wiesel TN (1974) Sequence regularity and geometry of orientation columns in the monkey striate cortex. J Comp Neurol 158:267-293. CrossRef Medline

Jacoby J, Zhu Y, DeVries SH, Schwartz GW (2015) An amacrine cell circuit for signaling steady illumination in the retina. Cell Reports 13:2663-2670. CrossRef Medline

Kay JN, De la Huerta I, Kim IJ, Zhang Y, Yamagata M, Chu MW, Meister M, Sanes JR (2011) Retinal ganglion cells with distinct directional preferences differ in molecular identity, structure, and central projections. J Neurosci 31:7753-7762. CrossRef Medline

Kier CK, Buchsbaum G, Sterling P (1995) How retinal microcircuits scale for ganglion cells of different size. J Neurosci 15:7673-7683. Medline

Kim IJ, Zhang Y, Yamagata M, Meister M, Sanes JR (2008) Molecular identification of a retinal cell type that responds to upward motion. Nature 452:478-482. CrossRef Medline

Kim JS, Greene MJ, Zlateski A, Lee K, Richardson M, Turaga SC, Purcaro M, Balkam M, Robinson A, Behabadi BF, Campos M, Denk W, Seung HS; EyeWirers (2014) Space-time wiring specificity supports direction selectivity in the retina. Nature 509:331-336. CrossRef Medline

Lee S, Zhou ZJ (2006) The synaptic mechanism of direction selectivity in distal processes of starburst amacrine cells. Neuron 51:787-799. CrossRef Medline

Lee SH, Kwan AC, Zhang S, Phoumthipphavong V, Flannery JG, Masmanidis SC, Taniguchi H, Huang ZJ, Zhang F, Boyden ES, Deisseroth K, Dan Y (2012) Activation of specific interneurons improves V1 feature selectivity and visual perception. Nature 488:379-383. CrossRef Medline

Lee S, Kim K, Zhou ZJ (2010) Role of ACh-GABA cotransmission in detecting image motion and motion direction. Neuron 68:1159-1172. CrossRef Medline

Lee S, Chen L, Chen M, Ye M, Seal RP, Zhou ZJ (2014) An unconventional glutamatergic circuit in the retina formed by vGluT3 amacrine cells. Neuron 84:708-715. CrossRef Medline

Levick WR (1967) Receptive fields and trigger features of ganglion cells in the visual streak of the rabbits retina. J Physiol 188:285-307. CrossRef Medline

Lien AD, Scanziani M (2013) Tuned thalamic excitation is amplified by visual cortical circuits. Nat Neurosci 16:1315-1323. CrossRef Medline

Livingstone MS (1998) Mechanisms of direction selectivity in macaque V1. Neuron 20:509-526. CrossRef Medline

Marshel JH, Kaye AP, Nauhaus I, Callaway EM (2012) Anterior-posterior direction opponency in the superficial mouse lateral geniculate nucleus. Neuron 76:713-720. CrossRef Medline

Murphy GJ, Rieke F (2006) Network variability limits stimulus-evoked spike timing precision in retinal ganglion cells. Neuron 52:511-524. CrossRef Medline

Murphy-Baum BL, Taylor WR (2015) The synaptic and morphological basis of orientation selectivity in a polyaxonal amacrine cell of the rabbit retina. J Neurosci 35:13336-13350. CrossRef Medline
Niell CM, Stryker MP (2008) Highly selective receptive fields in mouse visual cortex. J Neurosci 28:7520-7536. CrossRef Medline

Oesch N, Euler T, Taylor WR (2005) Direction-selective dendritic action potentials in rabbit retina. Neuron 47:739-750. CrossRef Medline

Oyster CW, Barlow HB (1967) Direction-selective units in rabbit retina: distribution of preferred directions. Science 155:841-842. CrossRef Medline

Passaglia CL, Troy JB, Rüttiger L, Lee BB (2002) Orientation sensitivity of ganglion cells in primate retina. Vis Res 42:683-694. CrossRef Medline

Pearson JT, Kerschensteiner D (2015) Ambient illumination switches contrast preference of specific retinal processing streams. J Neurophysiol 114:540-550. CrossRef Medline

Piscopo DM, El-Danaf RN, Huberman AD, Niell CM (2013) Diverse visual features encoded in mouse lateral geniculate nucleus. J Neurosci 33:46424656. CrossRef Medline

Schwartz GW, Okawa H, Dunn FA, Morgan JL, Kerschensteiner D, Wong RO, Rieke F (2012) The spatial structure of a nonlinear receptive field. Nat Neurosci 15:1572-1580. CrossRef Medline

Sümbül U, Song S, McCulloch K, Becker M, Lin B, Sanes JR, Masland RH, Seung HS (2014) A genetic and computational approach to structurally classify neuronal types. Nat Commun 5:3512. Medline

Swindale NV, Shoham D, Grinvald A, Bonhoeffer T, Hübener M (2000) Visual cortex maps are optimized for uniform coverage. Nat Neurosci 3:822-826. CrossRef Medline

Trenholm S, Johnson K, Li X, Smith RG, Awatramani GB (2011) Parallel mechanisms encode direction in the retina. Neuron 71:683-694. CrossRef Medline

Venkataramani S, Taylor WR (2010) Orientation selectivity in rabbit retinal ganglion cells is mediated by presynaptic inhibition. J Neurosci 30: 15664-15676. CrossRef Medline

Völgyi B, Chheda S, Bloomfield SA (2009) Tracer coupling patterns of the ganglion cell subtypes in the mouse retina. J Comp Neurol 512:664-687. CrossRef Medline

Wang L, Sarnaik R, Rangarajan K, Liu X, Cang J (2010) Visual receptive field properties of neurons in the superficial superior colliculus of the mouse. J Neurosci 30:16573-16584. CrossRef Medline

Wässle H, Puller C, Müller F, Haverkamp S (2009) Cone contacts, mosaics, and territories of bipolar cells in the mouse retina. J Neurosci 29:106-117. CrossRef Medline

Wei W, Elstrott J, Feller MB (2010) Two-photon targeted recording of GFPexpressing neurons for light responses and live-cell imaging in the mouse retina. Nat Protoc 5:1347-1352. CrossRef Medline

Wei W, Hamby AM, Zhou K, Feller MB (2011) Development of asymmetric inhibition underlying direction selectivity in the retina. Nature 469:402406. CrossRef Medline

Weliky M, Bosking WH, Fitzpatrick D (1996) A systematic map of direction preference in primary visual cortex. Nature 379:725-728. CrossRef Medline

Yacoub E, Harel N, Ugurbil K (2008) High-field fMRI unveils orientation columns in humans. Proc Natl Acad Sci U S A 105:10607-10612. CrossRef Medline

Yonehara K, Balint K, Noda M, Nagel G, Bamberg E, Roska B (2011) Spatially asymmetric reorganization of inhibition establishes a motionsensitive circuit. Nature 469:407-410. CrossRef Medline

Zhao X, Chen H, Liu X, Cang J (2013) Orientation-selective responses in the mouse lateral geniculate nucleus. J Neurosci 33:12751-12763. CrossRef Medline 